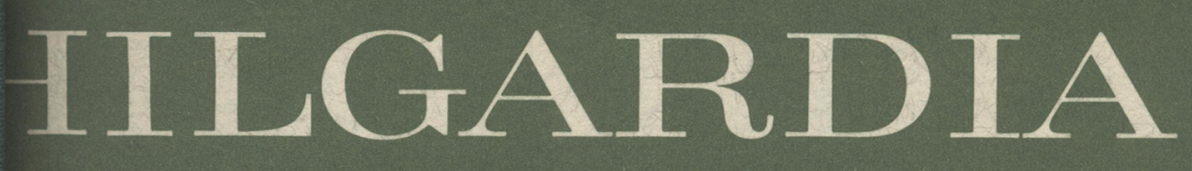

OURNAL OF AGRICULTURAL SCIENCE PUBLISHED BY CALIFORNIA AGR ICULTURALEXPERIMENTSTATION

Volume 44, Number $1 \cdot$ January, 1976

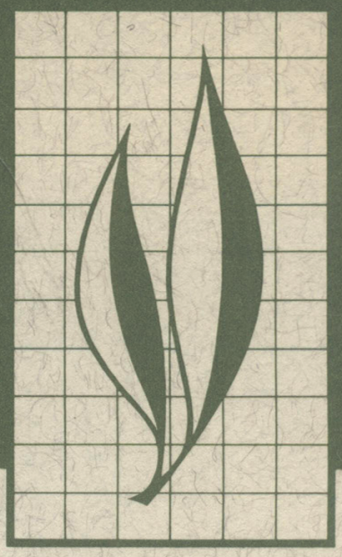

Determinants of Host Selection for Species of Aphytis (Hymenoptera: Aphelinidae),
Parasites of Diaspine Scales

John L. Baker 


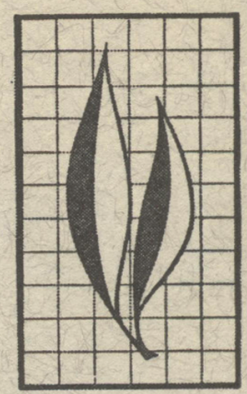

Host selection behavior in entomophagous insects is a series of reflex responses to physical and chemical stimuli. It was known that the host selection process for Apbytis, parasites of armored scales, utilized the stimulus of a water-soluble chemical contained in the scale cover and that physical features were unimportant. It was unknown whether the adult could exercise host discrimination and restrict oviposition to host species that were suitable for progeny development.

When given no choice of host species, the female is under physiological pressure to oviposit and does not discriminate. However, when a choice is present the female prefers to oviposit on the suitable host, though discrimination is not absolute. Suitability is determined by stimuli perceived both by the antennae and by the ovipositor, neither having predominant importance.

The scale molt stage is rejected as an oviposition site because of its hard condition, not because of a lack of an "air space" stimulus occurring between the cover and the body. With the cover removed, the second instar scale will continue development to the second molt stage. In that stage, it is free from the host fruit and can be transferred to another fruit where it will become a third instar, forming an entirely new cover.

Quick-frozen and defrosted hosts are readily accepted, showing that a movement stimulus or indeed the living condition is not necessary for oviposition.

Pre-imaginal conditioning may or may not occur, depending on the species of host. Such conditioning would not be a factor in mass rearing programs using $A$. melinus.

While ovipositing, Apbytis injects a venom into the host, preventing sclerotizing or molting. This prevents loss of the parasite egg due to host ecdysis.

\section{THE AUTHOR:}

John L. Baker is Research Entomologist, Department of Entomology, Davis. 


\section{Determinants of Host Selection for Species of Apbytis (Hymenoptera: Aphelinidae), Parasites of Diaspine Scales ${ }^{1}$}

\section{INTRODUCTION}

$T_{\text {he genus Aphytis howard (Hymen- }}$ optera: Chalcidoidea: Aphelinidae) are all obligatory ectoparasites of armored scale insects (Homoptera: Coccoidea: Diaspididae). These scales rank high among the major insect pests of orchard crops and ornamentals throughout the world, and various species of Aphytis are recognized as being the key agents in regulating population densities of many scale species in many countries (Compere, 1955; DeBach, 1960b, 1964, 1969; Huffaker et al., 1962; Lord and MacPhee, 1953). Thus the economic value of these natural enemies is wellestablished.

The biology and the host-selection behavior of Aphytis, which are similar to those of other hymenopterous parasites, have already been thoroughly described (DeBach and Landi, 1961; Quednau, 1964), and only a brief account will be given here. The female parasite searches randomly by walking on the host until a scale is found. The scale is then mounted and closely examined with the antennae (and perhaps the tarsi). If the scale is found attractive after this scrutiny, the parasite begins drilling through the scale's cover with her ovipositor, and with the cover penetrated the ovipositor is thrust deeply into the scale's body. If the host is found acceptable, an egg is laid exterior to the scale's

${ }^{1}$ Submitted for publication February 7, 1974. body but under its cover. The egg may be deposited on either the dorsum or ventrum, with the latter being the most common location. Each egg laid represents a separate attack, though the same scale may be attacked several times in succession by the same parasite. Thirdinstar female nymphs are the preferred host stage, but second-instar males and females, male prepupae and pupae, and adult scale females having a loosely attached cover will also be attacked.

Adult female Aphytis frequently feed on the host by constructing a feeding tube from the scale's cover to its body. First, the scale is drilled and probed as for egg laying, and then the parasite secretes material along its ovipositor. This material hardens around the ovipositor which acts as a mold. The parasite then withdraws her ovipositor, turns around, places her mouthparts at the end of the newly-formed tube, and sucks up the scale hemolymph.

The only definitive host-selection study of Aphytis was made by Quednau and Hübsch (1964) who worked with Aphytis coheni DeBach and A. holoxanthus DeBach using California red scale, Aonidiella aurantii (Mask.), and Florida red scale, Chrysomphalus aonidum (L.) as hosts. They state:

The female Aphytis recognizes its host by a stimulating sub- 
stance which is contained in the scale cover. This substance is perceived by the parasite by contact odor. If this substance is removed by water, the scale cannot be recognized by the parasite. The physical form of the scale cover does not play an important role. Oviposition of the parasite is dependent on the physiochemical structure of the body and the cover of the host. If the cover is removed, the scale is probed by the female Aphytis, but she does not oviposit there. The research has shown that citrus leaves are not more attractive in comparison to artificial paper leaves when the female searches for hosts.

The results of the experiment described here, which compares citrus leaves with that of artificial paper leaves are questionable. The parasites were kept in one-half of a Petri dish. Volatile chemicals emanating from a citrus leaf diffused throughout this chamber and probably obscured the comparison. Furthermore, the chamber was so small that one would expect random movement by the parasite to result in an equal frequency of visit to the two kinds of leaves, obliterating any differential attraction of the leaves themselves.

Other references to host selection in Aphytis are few. DeBach and Landi (1961) stated that host feeding by $A$. lepidosaphes Compere did not need to precede oviposition, indicating that gustatory stimuli were not used in host selection or at least were not necessary. DeBach and Sundby (1963) reported that Aphytis searches randomly by running and flying. Both real and artificial scales, as well as other objects such as sand grains, were examined by the parasites, and the females actually attempted to oviposit in the artificial scales. The parasites were attracted to the scales only at close distances ( 1 $\mathrm{cm})$, thus suggesting visual stimulation.

Striking differences in degrees of gregariousness exist among Aphytis species. Huffaker et al. (1962) report that the Persian form of $A$. maculicornis (Masi) has great ability to recognize previously parasitized hosts and thus avoids ovipositing on them. In the field it rarely deposits more than one egg on a host even when parasite densities are high. On the other hand, hosts previously visited but not at first parasitized are not neglected later. This indicates lack of host marking (spoor effect) by the females. By contrast, A. lepidosaphes larvae are generally gregarious (DeBach and Landi, 1961), and it is customary for two or more adults to emerge from each scale. A. melinus DeBach, $A$. fisheri DeBach, and $A$. lingnanensis Compere are likewise gregarious (DeBach and Sundby, 1963).

Numerous references to the host range of various Aphytis species (DeBach, 1959, 1960a, 1969: DeBach and Landi, 1961; Quednau, 1965; etc.) demonstrate that these parasites vary from strictly monophagous to at most oliphagous. What is lacking, however, is proof of whether (a) ovipositing adult females parasites have the ability to discriminate among hosts, restricting their oviposition to hosts which are suitable by species and by state of maturation and viability for development of the parasite's progeny, or (b) whether that suitability is determined by the ability of parasite larvae to develop. Also lacking is an analysis of the stimuli to which the females may respond in making this discrimination. The degree of discrimination of any Aphytis species would have considerable bearing on that species' efficiency as a natural enemy and its relative success in hostpopulation regulation. To obtain this information, host acceptability studies were conducted using two species of 
Aphytis. The following points were investigated:

- Whether ovipositing females can distinguish between hosts nutritionally suitable for their progeny and those nutritionally unsuitable.

- The relative roles of scale cover and scale body stimuli in the selection process.
- The basis on which molt stages are rejected as acceptable hosts.

- The acceptability of freshly-killed hosts.

- Whether pre-imaginal conditioning influences host preference.

- Host-stinging as an element of host suitability.

\section{MATERIALS AND METHODS}

\section{Maintenance of host-scale cultures}

All four species of armored scale insects used in this study were cultured in the insectary of the Division of Biological Control at the University of California, Riverside. To infest fruit the drop method was used exclusively. Lemons used were coated with paraffin on one side to prevent desiccation.

Cactus scale, Diaspis echinocacti Bouche, is biparental and was reared on mature cactus pads (Opuntia spp.) which were cut from plants grown for this reason at the Biological Control Grove at U.C.R. The culture was kept at about $27^{\circ} \mathrm{C}$ and about 60 per cent R. H. (relative humidity) with the infestation period being 2 days. Under these conditions, scales reached the third instar stage about 30 days after settling, after which they were suitable for parasitization until they were about 7 weeks old.

Latania scale, Hemiberlesia lataniae (Sign.) was grown on russet potato tubers at about $27^{\circ} \mathrm{C}$ and about 80 per cent R. H., with a 1 -week infestation period. It is uniparental, and the scales become suitable in about 40 days, remaining so for an additional 2 weeks.

The uniparental oleander scale, $A s$ pidiotus hederae (Vallot), was propagated on lemons and on russet potato tubers. Potatoes with crawler-producing adults were used as the parent stock to infest lemons and more potatoes. The infestation period was 1 day for lemons and 1 week for potatoes. At about $23^{\circ}$
$\mathrm{C}$ and 50 to 60 per cent $\mathrm{R}$. H. the scales became second instars in 19 to 20 days and third instars at 34 days. Their suitability ends at about 60 days.

Potatoes and lemons were also used to raise California red scale-potatoes for the parent stock and lemons for the parasites. Potatoes had a week of infesting, but lemons had only 1 day. At about $27^{\circ} \mathrm{C}$ and 50 to 60 per cent R. $\mathrm{H}$. the third instar stage was reached in 21 days, but mated females became unsuitable in only 7 more days because they became closely attached to the scale covers (as did the molt stages). The second instar stage began after 13 days. While females were in second molt and early third instar, males were going through prepupal and pupal stages, emerging to mate while the females were in middle third instar. Second instar females and male second instars and prepupae were suitable hosts, but yielded smaller parasites.

\section{Maintenance of parasite cultures}

The two parasite species employed in this study were $A$. melinus and $A$. $m y$ tilaspidis LeBaron form 3c (DeBach, 1964). The first, obtained from California red scale on citrus in southern California, is arrhenotokous and was cultured on oleander scale. The second is thelytokous and originated from latania scale on Ficus sp. in Crete; it was reared on both latania and cactus scale.

Each parasite culture was maintained in the insectary at about $27^{\circ} \mathrm{C}$ and 50 
per cent $R . H$. in a 1-hole sleeve cage with the length of the life cycle of these parasites being about 3 weeks. These cages can accommodate five wire trays of scale host material. Each week a tray of new host material was added to the top shelf and previous trays were moved down one shelf and the oldest tray discarded. Because most caged parasites tended to congregate on the lower side of the host potato, lemon, or cactus pad, that side of the host fruit having the greatest density of scales was placed facing downwards to maximize parasitization. When new scales were provided, honey was streaked on the underside of the glass top of the cage to provide a carbohydrate source for the adult parasites.

\section{General parasite-handling procedures}

Parasites were obtained by first isolating them in the late pupal stage. Host fruits bearing parasitized scales were removed from a culture and examined under a dissecting microscope at $10 \mathrm{X}$. Scale covers were lifted with an insect pin, and when a parasite pupa was found it was picked up with a small camel's-hair brush and placed in a 1/4dram vial provided with honey. These vials were plugged with cotton and placed on a holed board to await adult emergence. In each experiment, adults were utilized within 12 hours after eclosion and always in a virgin condition.

\section{INFLUENCE OF DIASPINE SCALE COVERS AND BODIES ON HOST DISCRIMINATION BY APHYTIS}

The stimuli responsible for host discrimination in host acceptance by Aphytis are unknown, if indeed such discrimination actually occurs. The following experiments were designed to determine whether Aphytis adults can (1) distinguish between suitable and unsuitable hosts, (2) restrict oviposition to only those hosts suitable for the parasites' progeny, and (3) use the scale cover, the scale body, or both in making this discrimination. Host discrimination could be quantified by egg counts, as each egg laid represents a separate attack and each act of oviposition requires host discrimination.

\section{MATERIALS AND METHODS}

The A. mytilaspidis LeBaron form 3c (DeBach, 1964) was used exclusively in this series of tests. It reproduces equally well on either latania scale or cactus scale, but essentially fails to reproduce on California red scale or oleander scale even though many eggs may be laid on these last two. Thus, distinct and contrasting differences in host suitability were present.

Scale bodies and covers being tested were attached to a No. 1-18 mm circular microscope cover glass in a random arrangement. Each third instar scale body on the host fruit was first removed from its cover and then laid ventral side down on the cover glass; six or more minute drops of honey were applied to the perimeter of the scale cover, which was then placed over the scale body and secured. Scale bodies were never combined with their natural covers. Four identical cover body combinations per cover glass were used in the "no-choice" tests; for "choice" tests, six combinations per cover glass were used, three of each kind.

Individual parasite females were then anesthetized briefly with $\mathrm{CO}_{2}$ and dropped into the test chambers, which consisted of 3 -inch $\times 1$-inch slides each having a depression $3 \mathrm{~mm}$ deep and 16 $\mathrm{mm}$ wide. The scale-bearing cover glass, held by honey drops, was then applied before the parasite could recover, so 


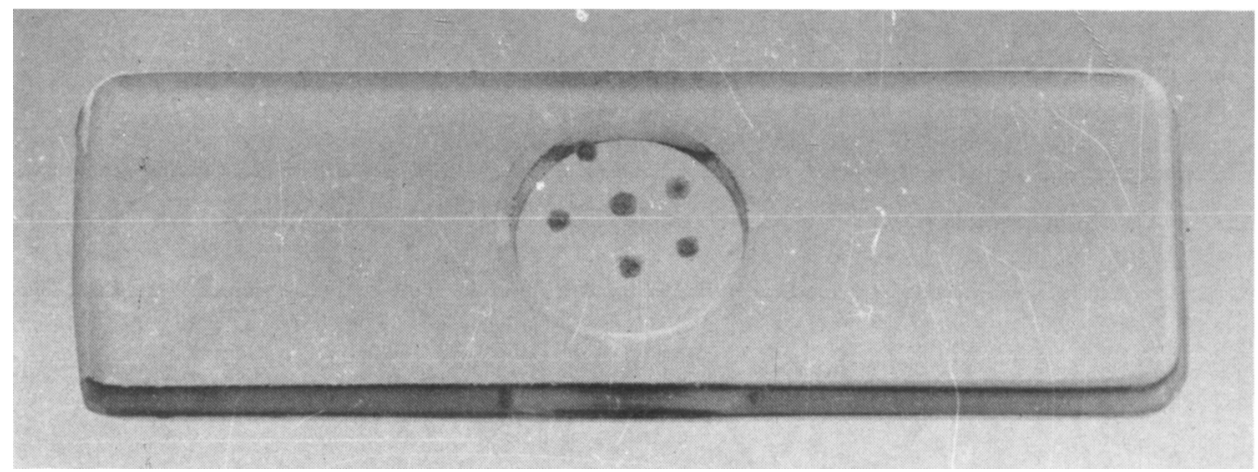

Fig. 1. Depression slide test chamber with scale-bearing coverglass.

that the scales were in an inverted position (fig. 1; DeBach and Landi, 1961). There was sufficient honey protruding from beneath the scale cover margins, and in the drops securing the cover glass, to provide nutrition for the parasites.

Each experimental chamber containing parasite and scales was placed on a table above a flat sheet of grey cardboard. A desk lamp directly above provided a continuous illumination of 24 foot-candle power. Preliminary tests showed that oviposition could usually be expected to occur at least once during an exposure of 6 hours, so a 6 -hour oviposition period was allowed. At the end of the test period the cover was lifted, the adult parasite was removed and destroyed, and the number of eggs deposited in each combination was counted and scored. Whenever oviposition failed to occur, the test was repeated under the assumption that the artificiality of the test prevented normal oviposition behavior, or that the parasites were not under pressure to oviposit.

Records kept of host-mutilation marks on scale bodies indicated that host probing without oviposition occurred on both preferred and unpreferred hosts and that oviposition without probing also occurred on both types of hosts. No significant pattern of this was apparent when comparing hosts, however.

Ten replicates were performed in the no-choice test, and results were analyzed by a 1-way analysis of variance. The choice tests were repeated until the egg count reached or exceeded a minimum of 100 eggs, regardless of the number of replicates; these results were analyzed by a $\mathrm{X}^{2}$ test of goodness of fit, with the hypothetical ratio of $1: 1$ indicating randomness or no discrimination.

\section{No-choice tests of absolute discrimination}

Cactus scale, a preferred host, and California red scale, an unpreferred host, were used in tests designed to see whether parasites would refuse to oviposit on the unpreferred host (absolute discrimination). By switching scale covers, four possible combinations of scale covers and scale bodies were available, and each of the four kinds were separately offered to the parasites. It was anticipated that where scale species were mixed (viz., cactus scale covers over red scale bodies and red scale covers over cactus scale bodies) the parasites would be deceived to some extent so that some oviposition would occur, but that the number of eggs laid would be less than when the preferred host alone was offered, although greater than when the unpreferred host alone was offered. Table 1 shows the results.

About the same number of eggs was laid in each test, and a 1-way analysis of variance shows no significant differ- 
TABLE 1

NUMBERS OF PARASITE EGGS PRODUCED ON FOUR SCALES USING VARIOUS SCALE COVER OVER SCALE BODY COMBINATIONS IN NO-CHOICE TESTS

\begin{tabular}{|c|c|c|c|c|c|c|c|c|c|c|c|c|c|c|c|}
\hline \multicolumn{16}{|c|}{ Scale cover over scale body combinations* } \\
\hline \multicolumn{4}{|c|}{$\frac{0}{0}$} & \multicolumn{4}{|c|}{$\frac{\mathbf{0}}{\mathbf{R}}$} & \multicolumn{4}{|c|}{$\frac{\mathbf{R}}{\mathbf{0}}$} & \multicolumn{4}{|c|}{$\frac{\mathbf{R}}{\mathbf{R}}$} \\
\hline 0 & 1 & 1 & 1 & 1 & 2 & 2 & 1 & 1 & 1 & 1 & 3 & 2 & 2 & 1 & 1 \\
\hline 1 & 2 & 0 & 1 & 0 & 2 & 2 & 0 & 1 & 2 & 0 & 1 & 1 & 2 & 0 & 8 \\
\hline 2 & 0 & 0 & 0 & 2 & 1 & 1 & 0 & 8 & 4 & 1 & 0 & 1 & 1 & 1 & 0 \\
\hline 0 & 0 & 1 & 2 & 0 & 0 & 2 & 1 & 0 & 1 & 0 & 1 & 2 & 2 & 2 & 0 \\
\hline 1 & 1 & 0 & 0 & 0 & 0 & 0 & 1 & 1 & 2 & 0 & 1 & 1 & 2 & 1 & 2 \\
\hline 2 & 0 & 0 & 2 & 0 & 0 & 1 & 0 & 0 & 2 & 0 & 2 & 0 & 0 & 1 & 0 \\
\hline 1 & 1 & 0 & 2 & 1 & 1 & 1 & 8 & 2 & 2 & 0 & 0 & 1 & 1 & 0 & 0 \\
\hline 2 & 1 & 0 & 0 & 0 & 2 & 0 & 2 & 0 & 0 & 0 & 1 & 2 & 2 & 1 & 1 \\
\hline 1 & 2 & 2 & 1 & 1 & 2 & 0 & 0 & 2 & 0 & 2 & 0 & 1 & 1 & 0 & 0 \\
\hline 0 & 2 & 1 & 1 & 1 & 1 & 2 & 1 & 8 & 1 & 1 & 0 & 0 & 0 & 2 & 1 \\
\hline & & & 35 & & & & 87 & & & & 42 & & & & 41 \\
\hline
\end{tabular}

$\star O=$ cactus scale; $R=$ red scale; $0=$ oleander scale; $L=$ latania scale. Thus $\frac{0}{0}=$ cactus scale cover over cactus scale body, etc.

$\dagger 1$-way analysis of variance, $\mathrm{F}=0.3475$.

ence between the totals. This means that the parasites did not have the ability to discriminate absolutely and that the author's hypothesis about mixing scale species during cover switching was incorrect. This contrasts with the findings of Drooze \& Fedde (1972). This should not be interpreted as meaning that the parasites cannot distinguish between a suitable and unsuitable host, for they were not offered that choice. It does mean that (1) in the absence of a choice the parasites were under physiological pressure to oviposit with resultant ovipasition on unusual or unsuitable hosts, and (2) that during a similar time period as many eggs can be expected to be laid on unsuitable hosts as on suitable hosts because of this pressure. If these facts apply to a field situation as well as to a laboratory one, it would account for some of the peculiar host records for Aphytis reared from field-collected material.

\section{Choice tests: discrimination between preferred and unpreferred hosts}

The previous test showed that host discrimination is not infallible, so the question arises as to whether Aphytis has the ability to discriminate at all. This was tested by simultaneously offering both preferred and unpreferred hosts. In test 1 , the choice was between cactus scale as preferred host and red scale as unpreferred; in test 2 , cactus scale (preferred) and oleander scale (unpreferred) were offered together. Table 2 presents the results.

Both the tests show that the adult female parasite is capable of distinguishing between a suitable and an unsuitable host and that she prefers to oviposit on species on which her progeny can develop, although the discrimination is not without error. Therefore, the suitability of the scale species for larval development is determined by the adult female parasite and not by the larva after eclosion.

\section{Discrimination between bodies under preferred covers}

Aphytis uses its antennae to examine the host, but whether it uses the ovipositor in host discrimination had never been shown. To investigate this, parasites were presented preferred and unpreferred scale bodies under preferred 
TABLF 2

NUMBERS OF PARASITE EGGS PRODUCED ON SIX SCALES USING PREFERRED (CACTUS) AND UNPREFERRED (RED AND OLEANDER) SCALE COVERS AND BODIES IN CHOICE TEST

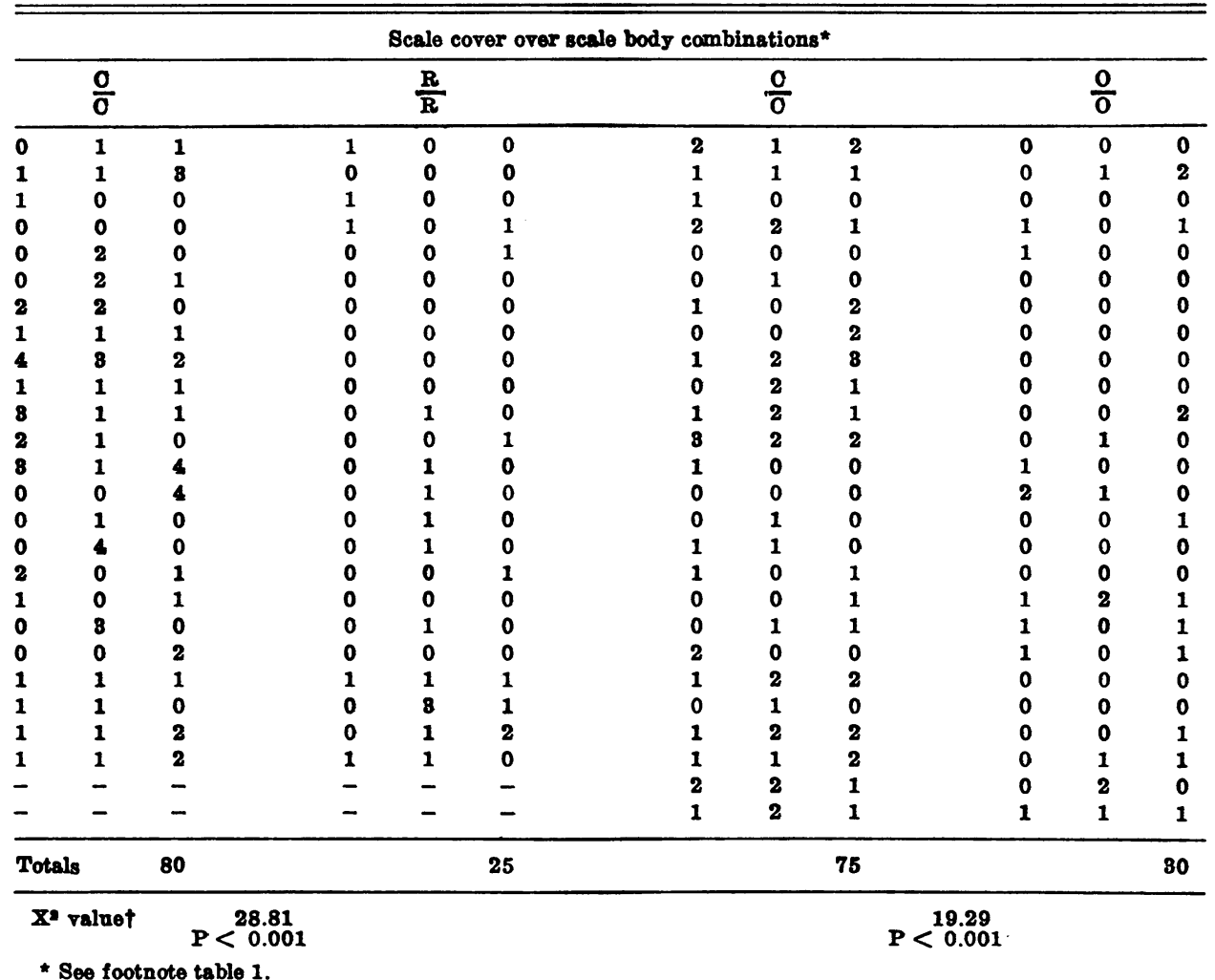

$\uparrow$ Hypothetical $1: 1$ ratio $=$ no discrimination.

host covers. In the first test, cactus scale and red scale bodies under cactus scale covers were exposed to adult parasites. The second test used cactus scale and oleander scale bodies under cactus scale covers. Table 3 shows the egg count.

Significantly more eggs were laid on the cactus seale bodies than on the red scale bodies or on oleander scale bodies. Even more striking was the sharp drop in magnitude of $X^{2}$ values from those in previous tests-this means that the parasites were deceived by preferred covers above unpreferred bodies. Stimulated by cactus scale cover, they were less likely to be dissuaded from ovipositing on the red scale or oleander scale bodies underneath.
The highly significant $\mathbf{X}^{2}$ values seem to indicate that the adult female's ovipositor has a sensory mechanism capable of evaluating the suitability of the host species. Possibly, however, an uninterrupted sequence of proper stimuli caused the significant majority of eggs to be laid on cactus scale bodies. When parasites were examining the cactus scale covers over cactus scale bodies only one species of host was present; possibly, then, the chemical stimulus causing acceptance of the body was the same stimulus causing acceptance of the cover.

On the other hand, when parasites were examining red scale or oleander scale bodies, two host species were in- 
TABLE 3

NUMBERS OF PARASITE EGGS PRODUCED ON SIX SCALES USING PREFERRED (CACTUS) SCALE COVERS OVER PREFERRED AND UNPREFERRED (RED AND OLEANDER) SCALE BODIES IN CHOICE TEST

\begin{tabular}{|c|c|c|c|c|c|c|c|c|c|c|c|}
\hline \multicolumn{12}{|c|}{ Scale cover over scale body cambinations * } \\
\hline \multicolumn{3}{|c|}{$\frac{0}{0}$} & \multicolumn{3}{|c|}{$\frac{\mathrm{d}}{\mathrm{R}}$} & \multicolumn{3}{|c|}{$\frac{0}{0}$} & \multicolumn{3}{|c|}{$\frac{0}{0}$} \\
\hline 1 & 0 & 1 & 0 & 0 & 0 & 0 & 1 & 1 & 1 & 1 & 0 \\
\hline 1 & 0 & 1 & 0 & 0 & 2 & 0 & 0 & 0 & 0 & 0 & 1 \\
\hline 0 & 0 & 1 & 0 & 1 & 0 & 1 & 0 & 1 & 0 & 0 & 0 \\
\hline 1 & 1 & 1 & 1 & 0 & 0 & 2 & 0 & 1 & 1 & 0 & 0 \\
\hline 1 & 1 & 0 & 1 & 0 & 0 & 0 & 1 & 1 & 0 & 0 & 1 \\
\hline 1 & 0 & 0 & 1 & 0 & 0 & 2 & 0 & 0 & 0 & 0 & 0 \\
\hline 1 & 1 & 1 & 0 & 0 & 0 & 0 & 0 & 2 & 0 & 0 & 0 \\
\hline 1 & 1 & 0 & 0 & 0 & 1 & 0 & 2 & 1 & 0 & 0 & 0 \\
\hline 0 & 0 & 0 & 1 & 0 & 0 & 1 & 0 & 1 & 0 & 0 & 0 \\
\hline 1 & 1 & 0 & 1 & 0 & 1 & 2 & 1 & 1 & 0 & 0 & 0 \\
\hline 2 & 0 & 1 & 0 & 0 & 1 & 1 & 0 & 1 & 1 & 1 & 0 \\
\hline 1 & 0 & 1 & 0 & 1 & 1 & 1. & 1 & 2 & 0 & 1 & 0 \\
\hline 1 & 0 & 0 & 2 & 0 & 0 & 1 & 2 & 0 & 0 & 1 & 0 \\
\hline 1 & 1 & 0 & 0 & 0 & 0 & 1 & 1 & 2 & 0 & 2 & 2 \\
\hline 0 & 1 & 3 & 0 & 0 & 0 & 1 & 1 & 2 & 1 & 1 & 0 \\
\hline 0 & 0 & 2 & 2 & 1 & 0 & 0 & 2 & 1 & 0 & 1 & 1 \\
\hline 2 & 0 & 1 & 1 & 1 & 0 & 1 & 0 & 0 & 1 & 1 & 0 \\
\hline 1 & 0 & 1 & 2 & 0 & 1 & 0 & 1 & 2 & 0 & 0 & 0 \\
\hline 2 & 0 & 1 & 0 & 1 & 0 & 8 & 1 & 1 & 1 & 0 & 0 \\
\hline 0 & 1 & 1 & 0 & 2 & 0 & 0 & 1 & 3 & 0 & 1 & 0 \\
\hline 2 & 1 & 1 & 1 & 1 & 1 & 2 & 0 & 2 & 2 & 0 & 1 \\
\hline 1 & 1 & 0 & 0 & 2 & 1 & 0 & 1 & 0 & 0 & 0 & 0 \\
\hline 3 & 0 & 2 & 0 & 1 & 0 & 2 & 0 & 1 & 8 & 1 & 1 \\
\hline 1 & 3 & 2 & 1 & 2 & 0 & 0 & 2 & 1 & 1 & 0 & 1 \\
\hline 1 & 8 & 1 & 2 & 1 & 0 & 0 & 2 & 1 & 2 & 1 & 2 \\
\hline$T_{0}$ & & 64 & & & 89 & & & 69 & & & 36 \\
\hline & & & & & & & & & & & \\
\hline
\end{tabular}

* See footnote table 1.

$\dagger$ See footnote table 2.

cluded in the combination-one species of cover and a second species of body. This disparity might have been what was detected by the parasites and caused them to favor the cactus-cover cactus-body combination. The problem could be solved by offering preferred and unpreferred bodies under unpreferred covers, and that was done in the next test.

\section{Discrimination between bodies under unpreferred covers}

Red scale and cactus scale bodies were offered in the standard manner under red scale covers; oleander scale and cactus scale bodies were presented under oleander scale covers. Table 4 shows counts for these tests.
Table 4 data show that, when choosing between cactus scale and red scale bodies, the parasites were able to detect the presence of the cactus scale body and to oviposit a significant majority of their eggs there even when it was under an unpreferred cover. The same was true of the comparison between cactus scale and oleander scale bodies. The fact that this discrimination occurred even when the preferred scale body was under the cover of another scale species shows that the "interruption of stimuli" argument was not a valid explanation of the results shown in table 3 . Indeed, data in tables 3 and 4 show conclusively that Aphytis parasites have a sensory receptor (s) in their ovipositors which can be used to detect host suitability. 
TABLE 4

NUMBERS OF EGGS PRODUCED ON SIX SCALES USING UNPREFERRED (RED AND OLEANDER) SCALE COVERS OVER PREFERRED (CACTUS) AND UNPREFERRED SCALE BODIES IN CHOICE TEST

\begin{tabular}{|c|c|c|c|c|c|c|c|c|c|c|c|}
\hline \multicolumn{12}{|c|}{ Scale cover over scale body combination * } \\
\hline & $\frac{R}{0}$ & & & $\frac{R}{R}$ & & & $\frac{0}{0}$ & & & $\frac{0}{0}$ & \\
\hline 2 & 0 & 0 & 0 & 0 & 0 & 2 & 1 & 2 & 0 & 1 & 0 \\
\hline 1 & 0 & 0 & 1 & 0 & 0 & 0 & 0 & 1 & 1 & 0 & 0 \\
\hline 1 & 1 & 2 & 1 & 2 & 1 & 2 & 1 & 0 & 0 & 0 & 1 \\
\hline 1 & 1 & 0 & 1 & 1 & 0 & 0 & 1 & 0 & 0 & 0 & 0 \\
\hline 0 & 1 & 0 & 0 & 0 & 1 & 0 & 1 & 0 & 0 & 0 & 0 \\
\hline 1 & 1 & 0 & 1 & 1 & 1 & 0 & 2 & 0 & 2 & 0 & 0 \\
\hline 2 & 1 & 1 & 0 & 0 & 0 & 0 & 0 & 1 & 0 & 0 & $\mathbf{0}$ \\
\hline 1 & 0 & 0 & 0 & 1 & 0 & 1 & 0 & 0 & 1 & 1 & 0 \\
\hline 8 & 1 & 8 & 1 & 0 & 0 & 0 & 1 & 1 & 0 & 0 & 0 \\
\hline 1 & 2 & 1 & 0 & 0 & 0 & 0 & 0 & 2 & 0 & 1 & 0 \\
\hline 1 & 1 & 1 & 2 & 0 & 0 & 1 & 1 & 0 & 0 & 0 & 1 \\
\hline 2 & 2 & 1 & 2 & 1 & 0 & 0 & 8 & 0 & 0 & 0 & 0 \\
\hline 1 & 2 & 1 & 1 & 1 & 0 & 1 & 0 & 0 & 1 & 0 & 0 \\
\hline 0 & 0 & 4 & 0 & 1 & 0 & 2 & 0 & 0 & 0 & 1 & 0 \\
\hline 1 & 1 & 2 & 1 & 1 & 2 & 1 & 1 & 0 & 2 & 2 & 0 \\
\hline 0 & 0 & 1 & 0 & 2 & 0 & 0 & 0 & 8 & 0 & 0 & 0 \\
\hline 1 & 0 & 2 & 1 & 0 & 0 & 2 & 1 & 1 & 0 & 1 & 1 \\
\hline 1 & 0 & 1 & 1 & 0 & 1 & 1 & 1 & 0 & 0 & 0 & 0 \\
\hline 0 & 0 & 1 & 1 & 0 & 0 & 1 & 1 & 0 & 0 & 0 & 0 \\
\hline 0 & 1 & 1 & 0 & 1 & 1 & 1 & 1 & 0 & 0 & 1 & 0 \\
\hline 1 & 1 & 0 & 0 & 0 & 0 & 0 & 0 & 2 & 1 & 0 & 1 \\
\hline 0 & 0 & 0 & 1 & 1 & 0 & 0 & 1 & 2 & 0 & 1 & 2 \\
\hline 0 & 0 & 1 & 0 & 0 & 0 & 1 & 0 & 2 & 2 & 3 & 0 \\
\hline 1 & 8 & 1 & 1 & 0 & 0 & 2 & 0 & 0 & 1 & 1 & 0 \\
\hline - & - & - & - & - & - & 1 & 2 & 2 & 0 & 0 & 0 \\
\hline - & - & - & - & - & - & 2 & 2 & 1 & 0 & 0 & 1 \\
\hline- & - & - & - & - & - & 2 & 0 & 0 & 1 & 2 & 1 \\
\hline- & - & - & - & - & - & 1 & 1 & 2 & 0 & 0 & 0 \\
\hline Totals & & 65 & & & 86 & & & 68 & & & 85 \\
\hline $\mathbf{X}^{2}$ & & $P<\begin{array}{l}8.33 \\
0.005\end{array}$ & & & & & & & & & \\
\hline
\end{tabular}

+ See footnote table 2.

A comparison of table 4 with table 2 shows an obvious reduction in discrimination ability. This is explained by a lack of differential attractiveness of the scale covers in the first place, where both preferred and unpreferred bodies were covered by unpreferred covers. The parasites were less likely to select the suitable bodies when they were covered by unpreferred covers.

\section{Discrimination between covers over preferred bodies}

Having shown that the scale body was a stimulus for host selection in Aphytis, the role of the scale cover in host selec- tion needed analysis. This was accomplished by letting the parasite select between preferred and unpreferred covers above a preferred host: cactus scale and red scale covers over cactus scale bodies, and cactus scale and oleander scale covers over cactus scale bodies. Table 5 shows the results of this analysis. In both cases, the parasites significantly favored combinations having the preferred cover. Thus the scale cover as a stimulus has an important function in host selection, and mixing host species' bodies and covers reduces discrimination. 
TABLE 5

NUMBER OF EGGS PRODUCED ON SIX SCALES USING PREFERRED (CACTUS) AND UNPREFERRED (RED AND OLEANDER) SCALE COVERS OVER PREFERRED BODIES IN CHOICE TEST

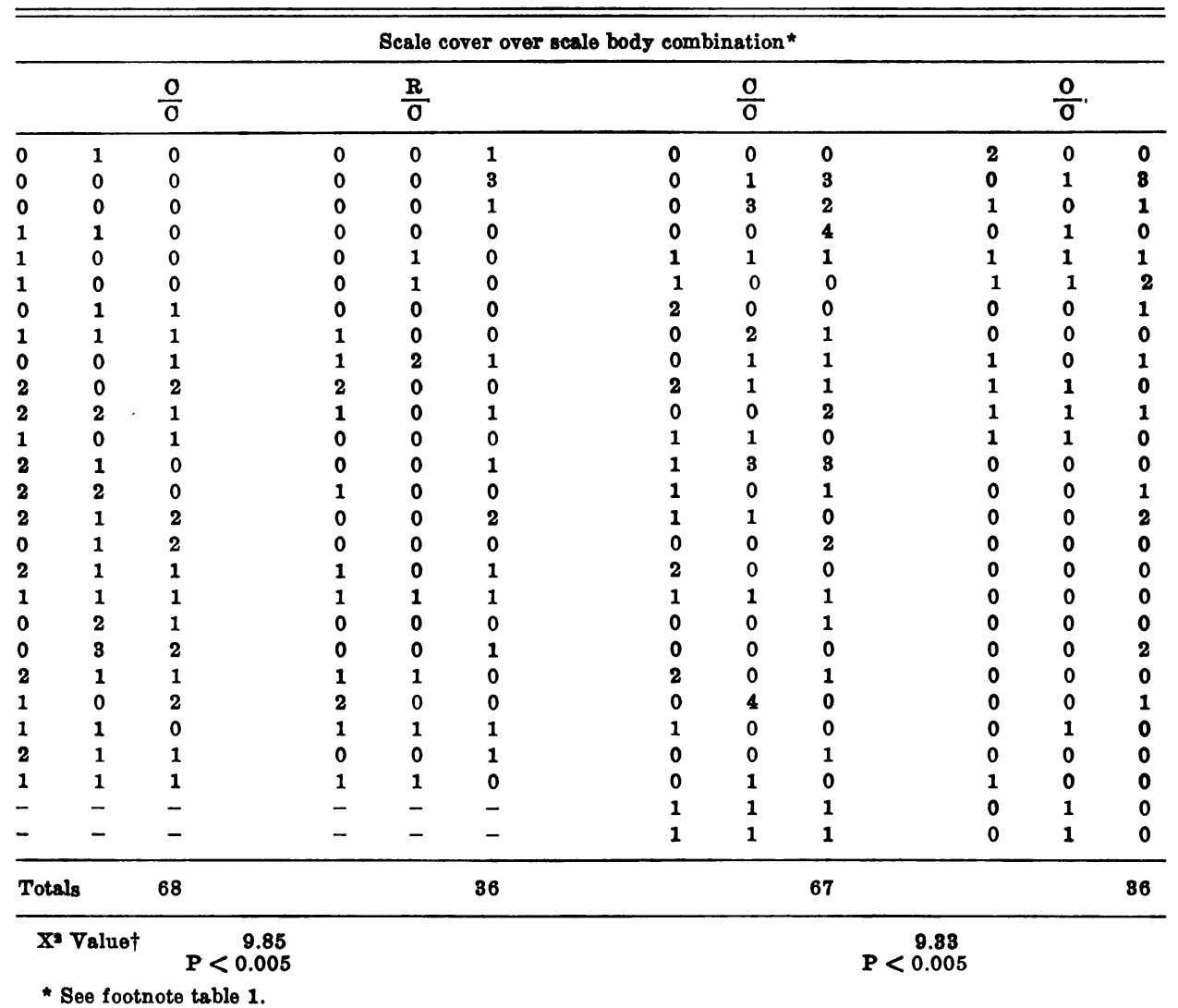

\section{Discrimination between covers over unpreferred bodies}

To test whether preferred hosts can be selected on the basis of the cover stimulus alone, parasites were allowed to select between preferred and unpreferred covers with unpreferred bodies beneath. The first choice involved cactus scale and red scale covers over red scale bodies. The second test compared cactus scale and oleander scale covers over oleander scale bodies. Table 6 shows the results.

The cactus scale cover was much preferred to the red scale cover, but no discrimination was made between cactus scale covers and oleander scale covers. Thus in one case the preferred cover was significantly selected, and in another case it was not.

\section{DISCUSSION}

To determine whether the scale body or the scale cover is more important for host discrimination in host acceptance, we can compare tests in which the preferred body was isolated among unpreferred stimuli with tests in which the preferred cover was isolated among unpreferred stimuli. The first two columns of tables 4 and 6 indicate that the parasites discriminated between preferred 
TABLE 6

NUMBER OF EGGS PRODUCED ON SIX SCALES USING PREFERRED (CACTUS) AND UNPREFERRED (RED AND OLEANDER) SCALE COVERS OVER UNPREFERRED BODIES IN CHOICE TEST

\begin{tabular}{|c|c|c|c|c|c|c|c|c|c|c|c|}
\hline \multicolumn{12}{|c|}{ Scale cover over scale body combination* } \\
\hline \multirow{2}{*}{\multicolumn{3}{|c|}{$\frac{\mathbf{0}}{\mathbf{R}}$}} & \multirow{2}{*}{\multicolumn{3}{|c|}{$\frac{\mathbf{R}}{\mathbf{R}}$}} & \multirow{2}{*}{\multicolumn{3}{|c|}{$\frac{0}{0}$}} & \multirow{2}{*}{\multicolumn{3}{|c|}{$\frac{0}{0}$}} \\
\hline & & & & & & & & & & & \\
\hline 2 & 0 & 2 & 0 & 0 & 0 & 1 & 2 & 1 & 1 & 1 & 0 \\
\hline 0 & 0 & 2 & 0 & 0 & 0 & 2 & 2 & 0 & 1 & 1 & 1 \\
\hline 8 & 0 & 0 & 1 & 0 & 1 & 1 & 0 & 2 & 2 & 1 & 1 \\
\hline 1 & 1 & 2 & 2 & 0 & 1 & 1 & 1 & 2 & 0 & 0 & 0 \\
\hline 8 & 2 & 2 & 1 & 1 & 0 & 0 & 0 & 0 & 0 & 1 & 1 \\
\hline 8 & 1 & 2 & 1 & 1 & 0 & 0 & 2 & 2 & 0 & 2 & 1 \\
\hline 1 & 1 & 0 & 0 & 0 & 1 & 1 & 0 & 0 & 1 & 2 & 0 \\
\hline 1 & 2 & 0 & 1 & 0 & 1 & 1 & 1 & 0 & 0 & 1 & 0 \\
\hline 2 & 1 & 0 & 0 & 2 & 0 & 2 & 0 & 1 & 1 & 0 & 2 \\
\hline 8 & 0 & 8 & 1 & 0 & 0 & 0 & 1 & 1 & 1 & 0 & 0 \\
\hline 1 & 0 & 2 & 1 & 0 & 0 & 1 & 2 & 1 & 0 & 1 & 0 \\
\hline 0 & 4 & $\overline{0}$ & 0 & 0 & 0 & 1 & 0 & 0 & 1 & 3 & 0 \\
\hline 1 & 2 & 1 & 1 & 0 & 1 & 0 & 2 & 1 & 0 & 0 & 3 \\
\hline $\mathbf{2}$ & 0 & $\mathbf{8}$ & 1 & 1 & 0 & 0 & 0 & 1 & 0 & 0 & 0 \\
\hline 1 & 1 & 0 & 0 & 0 & 0 & 1 & 1 & 1 & 1 & 1 & 1 \\
\hline 2 & 1 & 2 & 0 & 0 & 0 & 1 & 0 & 2 & 1 & 0 & 0 \\
\hline 0 & 0 & 1 & 0 & 1 & 1 & 2 & 0 & 1 & 0 & 1 & 1 \\
\hline 0 & 0 & 0 & 2 & 0 & 0 & 0 & 1 & 1 & 0 & 0 & 0 \\
\hline 0 & 0 & 1 & 2 & 0 & 0 & 0 & 1 & 0 & 2 & 3 & 0 \\
\hline 8 & 8 & 0 & 8 & 1 & 0 & 1 & 1 & 1 & 1 & 0 & 0 \\
\hline- & - & - & - & - & - & 0 & 1 & 0 & 1 & 0 & 2 \\
\hline- & - & - & - & - & - & 1 & 1 & 2 & 0 & 0 & 0 \\
\hline Totals & & 71 & & & 30 & & & 56 & & & 45 \\
\hline 2 & aluet & $\mathbf{P}$ & & & & & & & & & \\
\hline
\end{tabular}

and unpreferred covers more than they did between preferred and unpreferred bodies. However, the last two columns of the tables indicate the opposite conclusion. Thus we can interpret host selection in adult Aphytis as a function of cover and body stimuli with the degree of parasite discrimination and relative roles of the stimuli varying among host species.

\section{ACCEPTABILITY OF MOLT STAGE FOR PARASITE OVIPOSITION}

California red scale and yellow scale are nonsusceptible to parasitism by ectoparasites during the first molt stage of both sexes as well as the second molt and adult stages of the females. This is because the scale body in those stages is closely appressed to the scale cover, and presumably there is no space for an ectoparasite to deposit an egg (DeBach, 1969). The present study revealed that the cover adheres so tightly that it is nearly impossible to remove it intact from a normal red scale second molt. After a molt is completed, the upper half of the old exuvium is incorporated into the new scale cover. Then, as an instar stage, the scale body once again becomes free from the cover and susceptible to ectoparasites.

Quednau and Hübsch (1964) referred to the unsuitability of the molt stages of California red scale for host acceptability by Aphytis. Their conjecture was that the lack of an "air space" 


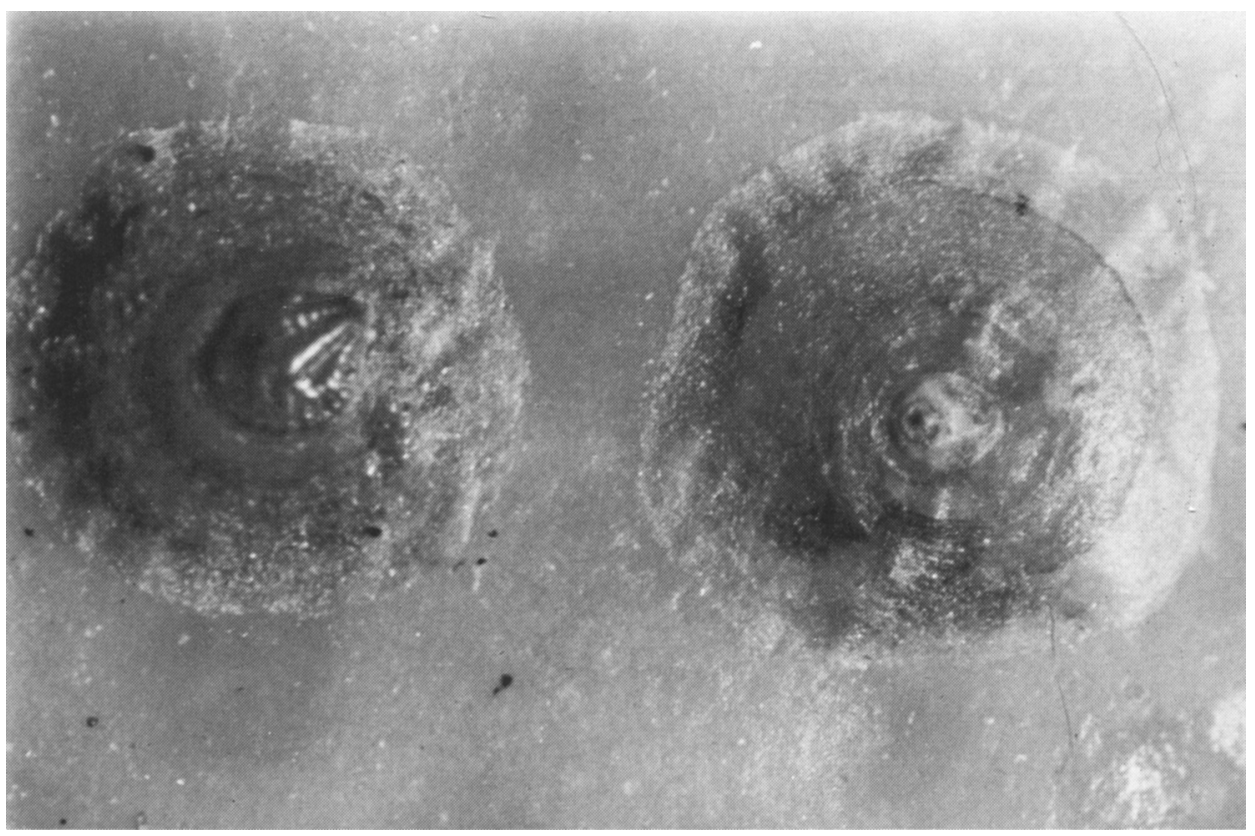

Fig. 2. Female third instar California red scale on lemon. Normal cover (right) and new cover formed after original cover was removed during second instar (left). Note prominent second exuvium at left.

between the scale cover and the scale body during molt stages breaks the sequence of proper stimuli for Aphytis parasites, and they ascribed rejection to this factor. (They further noted that the molt stages do not suffer host mutilation.)

In the present study it was observed that California red scale second instar females from which covers had been removed, but which were left on the host lemon, continued to develop and became hard and heavily sclerotized as they developed into the second molt stage. If left undisturbed, they completed the molt stage and went on to the third instar stage, forming a new scale cover minus the first exuvium, white cap, and nipple portions (fig. 2). It has also been observed (Bartlett and Fisher, 1950) that red scale parasites penetrate through the soft, waxy portion of the cover when they attack the host, thus avoiding the tough exuvium.

The second molt stages of oleander scales, which are also unsusceptible to Aphytis parasites (DeBach, 1969) were similarly examined. By comparison with red scale, ectoderm in the oleander scale molt is leathery rather than hard. The oleander scale cover is composed of more loosely woven wax fibers; it is closely attached to the molt body, but it can be lifted off intact without much difficulty. There is also an air space between the body and the cover" at the margin of the body where an ectoparasite could possibly place its egg. Despite these facts, the parasites reject the second molt stage. Red scale molt stages do not suffer host mutilation or host feeding because the parasites do not drill through the heavily sclerotized epidermis. The validity of the air space hypothesis could be checked by offering the parasites a choice between instar stages and molts whose covers were removed and then by checking them for oviposition and probing. 


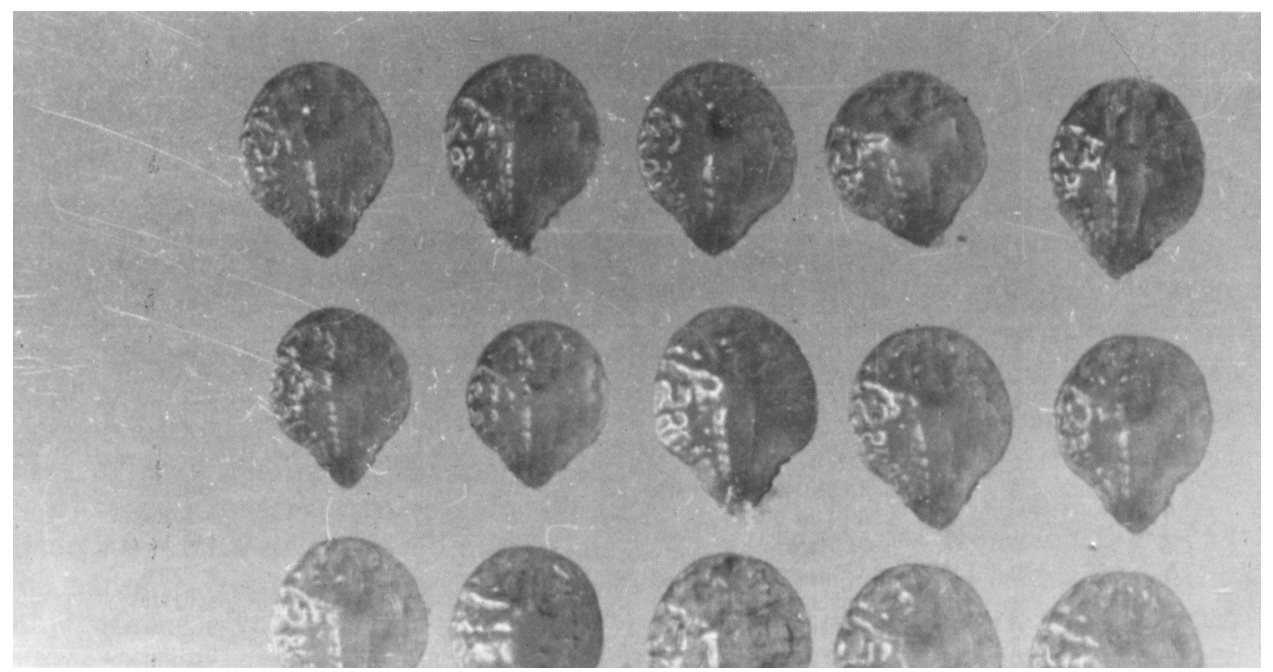

Fig. 3. Female California red scale second molts, formed after removal of second instar covers. Note heavy sclerotization.

\section{MATERIAL AND METHODS}

Molt stages were obtained by removing covers from second instar female California red scale. Lemons bearing these instars were placed on fruit stands inside a humidity box where the scales could develop without desiccation to the second molt stage; the conditions were $27^{\circ} \mathrm{C}$ and 80 per cent $\mathrm{R}$. H. They were ready for use in a few days and appeared as they do in figure 3 . The scales were easily lifted off the lemon with a fine paint brush, their mouthparts at that time being free from the lemon. Only plump, obviously healthy molts were used.

The slide apparatus and methods decribed previously were again used, but this time the parasite tested was $\boldsymbol{A}$. melinus, the dominant natural enemy of red scale in inland regions of southern California. In the first test the parasites were offered a choice between the second molts and second instars, both under third instar covers. The second test allowed a choice between second molts and third instars under third instar covers. A large air space existed between the molts and scale covers. Rep- lication was continued until the total number of eggs laid on the instars reached or exceeded 25. Egg counts were made at the end of the oviposition period.

After eggs had been counted, molts were removed from under the third instar covers, transferred to a fresh warm lemon and retained in the humidity box. The molts were observed over several succeeding days to determine whether they would come out of the molt stage, reinsert their rostrum, form a new cover, and continue living as third instar nymphs. Such activity by the scales was taken as an indication of a lack of host-probing by the parasites. Table 7 shows the results.

To further confirm the interaction between parasites and molts, four second molts were placed under third instar covers in the test chamber with two female $A$. melinus and observed through a dissecting microscope at $20 \mathrm{X}$ until ten separate attacks had been made. This was repeated for two more pairs of females, each pair having its own fresh molts and covers, until 30 attacks had been made. Notes were kept about 
TABLE 7

OVIPOSITION COUNTS OF APHYTIS MELINUS IN CHOOSING BETWEEN

CALIFONIA RED SCALE INSTARS AND SECOND MOLTS UNDER THIRD INSTAR COVERINGS: POST-TEST VIABILITY OF SCALE MOLTS AS SHOWN BY CONTINUED DEVELOPMENT

\begin{tabular}{|c|c|c|c|c|c|}
\hline $\begin{array}{l}\text { Bggs on } \\
\text { 2nd instar }\end{array}$ & $\begin{array}{l}\text { Eggs on } \\
\text { 2nd molt }\end{array}$ & $\begin{array}{c}\text { Stage of } \\
\text { development } \\
\text { of molt } \\
\text { after test }\end{array}$ & $\begin{array}{c}\text { Fggs on } \\
\text { 8rd instar }\end{array}$ & $\begin{array}{c}\text { Eggs on } \\
\text { 2nd molt }\end{array}$ & $\begin{array}{l}\text { Stage of } \\
\text { development } \\
\text { of molt } \\
\text { after test }\end{array}$ \\
\hline 1 & 0 & ecdysis* & 0 & 0 & Brd instar \\
\hline 0 & 0 & 3rd instar & 1 & 0 & ecdysis \\
\hline 2 & 0 & 3rd instar & 0 & 0 & 3rd instar \\
\hline 0 & 0 & 3rd instar & 1 & 0 & 3rd instar \\
\hline 0 & 0 & ecdysis & 2 & 0 & died as molt \\
\hline 1 & 0 & 3rd instar & 2 & 0 & ocdysis \\
\hline 1 & 0 & died as molt & 2 & 0 & 8rd instar \\
\hline 0 & 0 & 3rd instar & $\mathbf{8}$ & 0 & 8rd instar \\
\hline 1 & 0 & 3rd instar & 0 & 0 & ecdysis \\
\hline 0 & 0 & 3rd instar & 0 & 0 & ecdysis \\
\hline 1 & 0 & 3rd instar & 0 & 0 & 3rd instar \\
\hline 0 & 0 & died as molt & 2 & 0 & 8rd instar \\
\hline 0 & 0 & 3rd instar & 0 & 0 & died as molt \\
\hline 1 & 0 & 3rd instar & 1 & 0 & 3rd instar \\
\hline 1 & 0 & ecdysis & 0 & 0 & 8rd instar \\
\hline 0 & 0 & 8rd instar & 0 & 0 & 3rd instar \\
\hline 1 & 0 & 3rd instar & 0 & 0 & ecdysis \\
\hline 0 & 0 & ecdysis & $\mathbf{3}$ & 0 & 8rd instar \\
\hline 1 & 0 & Brd instar & 2 & 0 & died as molt \\
\hline 1 & 0 & 3rd instar & 2 & 0 & died as molt \\
\hline 2 & 0 & Brd instar & 1 & 0 & 3rd instar \\
\hline 1 & 0 & Brd instar & 2 & 0 & 8rd instar \\
\hline 0 & 0 & died as molt & 1 & 0 & 3rd instar \\
\hline 0 & 0 & ecdysis & 1 & 0 & 3rd instar \\
\hline 0 & $\mathbf{0}$ & ecdysis & & & \\
\hline 0 & 0 & 8rd instar & & & \\
\hline 1 & 0 & 3rd instar & & & \\
\hline 1 & 0 & died as molt & & & \\
\hline 1 & 0 & 3rd instar & & & \\
\hline 1 & 0 & 3rd instar & & & \\
\hline 0 & 0 & ecdysis & & & \\
\hline 1 & 0 & 3rd instar & & & \\
\hline 0 & 0 & Brd instar & & & \\
\hline 8 & 0 & Brd instar & & & \\
\hline 2 & 0 & ecdysis & & & \\
\hline 2 & 0 & 8rd instar & & & \\
\hline \multicolumn{6}{|l|}{ Totals } \\
\hline 27 & 0 & & 26 & 0 & \\
\hline
\end{tabular}

" "Ecdysis" means the scale died while changing fram the 2nd molt stage to the 3rd instar stage because it was unable to reinsert its new rostrum.

the action of the ovipositor while under the scale cover. The six parasites were then left for 24 hours in their test chambers under constant illumination to allow further interaction. Then the chambers were opened, covers were removed, and the molts were examined both for eggs and for their general condition.

RESULTS AND CONCLUSIONS

Discrimination between instars and molts was absolute (table 7) ; no statistical analysis needed to be applied. Molts were totally rejected as sites of oviposition. Rejection was not due to their smaller size in comparison with the preferred third instars; the second instars, which were smaller yet, were freely accepted.

For the most part, molts were unaffected by the parasites or by handling, and most of them continued develop- 
ment into the third instar stage after being placed on another lemon (table 7). Those whose development was terminated usually produced a new rostrum at least, showing that ecdysis had occurred before death; they were unsuccessful in reinserting the rostrum into the lemon, instead stringing it out over the surface of the lemon as a fine filament. This vitality indicates that their ectoderm was not pierced by the parasites' ovipositor during the experiment.

Microscope observation revealed that after a short period of acclimatization the parasites readily attacked third instar covers. The ovipositor rapidly pierced the scale cover, entering through the waxy grey margin. However, when the ovipositor tip contacted the hard sclerotized molt the shaft was thrust above and below the molt, but never through it. The female usually withdrew within a few seconds and either left or initiated another attack. The ovipositor was observed neither to pierce the molt nor to lay eggs.

After being with the parasites for 24 hours, the molts still appeared to be in good condition, being plump and not shriveled. In no case, however, had any eggs been laid, so even under ovipositional pressure the parasites restrained from laying eggs on the molts. Thus, while the ability of Aphytis adults to discriminate against unsuitable third instars when given no choice (table 1) is not good, their ability to discriminate against the unsuitable molt stage is absolute.

The California red scale second molt stage was rejected as a host even when a large air space, which could provide both a stimulus and a place for an ectoparasite egg, existed between it and the scale cover. Thus it may be concluded that the molt was rejected solely because of its tough ectoderm. Either the female parasite recognized that the hard surface of the molt is not a suitable site to lay an egg, or the lack of a proper stimulus due to no contact with a soft scale body surface prevented oviposition.

\section{ACCEPTABILITY OF FRESHLY-KILLED HOSTS}

Some species of parasites will oviposit on dead hosts while others require host movement as a stimulus for oviposition. Whether Aphytis will accept dead hosts could have significant bearing on their ability to regulate host scale populations, as well as perhaps on mass production if hosts could be quick-frozen and stored.

For instance, adults of some species of Aphytis do extensive host feeding. Sometimes they feed on a host and later ovipost on it; at other times they leave the host after feeding without laying an egg. Such a host soon dies, but until it becomes dried or putrified it is a suitable oviposition site for a parasite. Aphytis acceptance or rejection of freshly-killed hosts was investigated and is discussed in this section. A. mytilaspidis was the parasite used and materials and proce- dures described previously were again employed in this section.

Cactus scales were prepared by asphyxiation and quick freezing. To asphyxiate them, a small cactus pad bearing numerous third instar scales was placed in a screw-top 1-pint canning jar. The atmosphere in the jar was inundated with a strong flow of $\mathrm{CO}_{2}$ for 5 minutes, and a metal seal was then quickly applied and secured with a metal ring. The jar was then put in a dark place for 3 days to allow scales to die, after which it was opened and the scales, all of which were dead, were examined.

When first examined, the dead scales had their normal off-green color and turgid body condition and appeared to be in an acceptable condition for parasitization. At this time, the dead scales 
TABLE 8

NUMBER OF PARASITE EGGS PRODUCED ON LIVE AND DEAD THIRD INSTAR CACTUS SCALES KILLED BY $\mathrm{CO}_{2}$ IN CHOICE TEST

\begin{tabular}{|c|c|c|c|c|c|}
\hline \multicolumn{3}{|c|}{$\begin{array}{l}\text { Eggs on live } \\
\text { cactus scale }\end{array}$} & \multicolumn{3}{|c|}{$\begin{array}{l}\text { Eggs on dead } \\
\text { cactus scale }\end{array}$} \\
\hline 4 & 1 & 1 & 0 & 0 & 0 \\
\hline 0 & 2 & 0 & 0 & 0 & 0 \\
\hline 8 & 8 & 1 & 0 & 0 & 0 \\
\hline 0 & 0 & 2 & 0 & 0 & 1 \\
\hline 2 & 2 & 0 & 0 & 0 & 2 \\
\hline 2 & 0 & 5 & 0 & 0 & 0 \\
\hline 0 & 3 & 0 & 0 & 0 & 0 \\
\hline 0 & 1 & 1 & 0 & 0 & 0 \\
\hline 0 & 4 & 2 & 0 & 0 & 0 \\
\hline 2 & 1 & 3 & 0 & 0 & 0 \\
\hline 0 & 1 & 1 & 0 & 0 & 0 \\
\hline 1 & 1 & 0 & 0 & 0 & 0 \\
\hline 2 & 0 & 1 & 0 & 0 & 0 \\
\hline 1 & 2 & 0 & 0 & 0 & 0 \\
\hline 0 & 2 & 3 & 0 & 0 & 0 \\
\hline 1 & 0 & 0 & 0 & 0 & 0 \\
\hline 2 & 2 & 1 & 0 & 0 & 0 \\
\hline 2 & 1 & 1 & 0 & 0 & 0 \\
\hline 1 & 2 & 0 & 0 & 0 & 0 \\
\hline 2 & 1 & 0 & 0 & 0 & 0 \\
\hline 2 & 1 & 0 & 0 & 0 & 0 \\
\hline 1 & 4 & 1 & 0 & 0 & 0 \\
\hline 0 & 1 & 2 & 0 & 0 & 0 \\
\hline 1 & 8 & 1 & 0 & 0 & 0 \\
\hline 0 & 2 & 1 & 0 & 0 & 0 \\
\hline 2 & 2 & 1 & 0 & 0 & 0 \\
\hline als & & 01 & & & 3 \\
\hline
\end{tabular}

+ See footnote table 2.

and some live control scales were offered to the parasites in the depression slide chamber under third instar cactus scale covers. (The control scales had previously been examined with a compound microscope at $100 \mathrm{X}$ to assure that they were alive, the pulsating of the pharyngeal pump being used as an index of vitality.) During the next $1 / 2$ to 1 hour, however, the asphyxiated scales remaining on the pad started to turn brown, probably because of oxidation and at the end of 6 hours they were dark brown. Nevertheless, the scales in the chambers, as well as those on the pad, retained a high moisture content and appeared suitable for parasitization.

The quick-frozen scales were prepared by using a watch glass prechilled in a freezer unit to $6.7^{\circ} \mathrm{C}$. Vitality was checked as above, after which they were dropped into the chilled watch glass (which remained in the freezer) and left for 1 minute. Once removed and allowed a 15-minute warm-up period at room temperature, the frozen scales were reexamined and found to be dead, the pharyngeal pumps having ceased to pulsate. The control scales were similarly examined to be certain that they were alive.

Immediately after the frozen scales had been examined, both they and the control scales were covered with third instar cactus scale covers and presented to parasites in depression slide chambers.

TABLE 9

NUMBER OF PARASITE EGGS

PRODUCED ON LIVE AND DEAD

THIRD INSTAR CACTUS SCALES

KILLED BY QUTCK-FREEZING IN CHOICE TEST

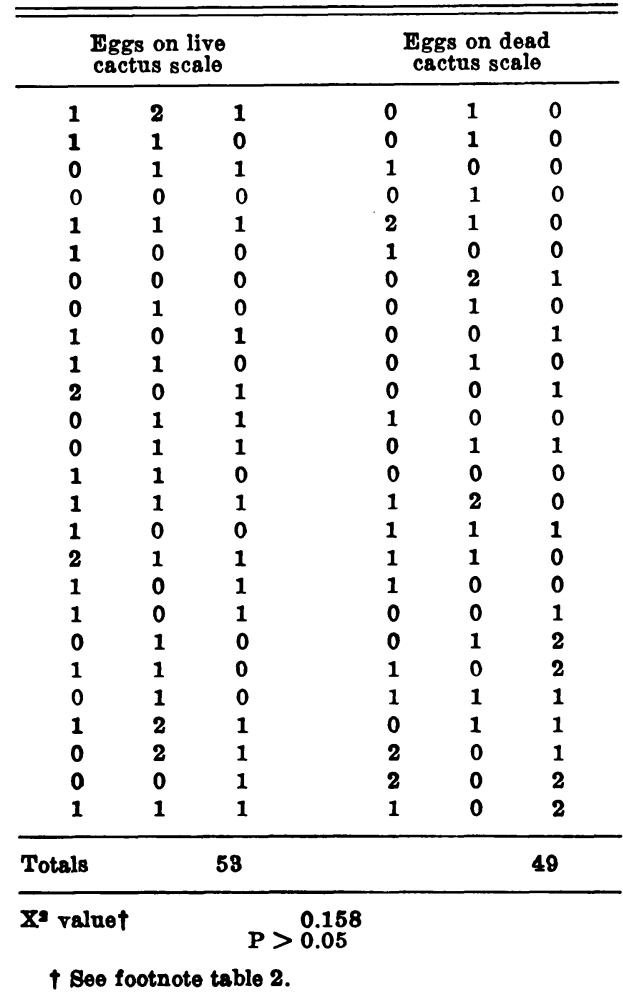


Tables 8 and 9 show ovipositional response of the parasites to scales killed by asphyxiation and quick-freezing. Acceptance of the quick-frozen hosts shows that Aphytis will accept a dead host and that a host-movement stimulus is not necessary for oviposition. Rejection of the asphyxiated hosts was probably due to their putrefaction or possibly to a high $\mathrm{CO}_{2}$ content in their hemolymph. Acceptance of the quick-frozen scales suggests that, in nature, a host recently killed by host feeding would probably be successfully utilized as a host.

\section{INVESTIGATIONS OF PRE-IMAGINAL CONDITIONING}

Host preference of the ichneumon Exidechthis canescens (Grav.) was found by Thorpe and Jones (1937) to be influenced by the host from which the parasite was reared. When parasites were reared on Anagasta kühniella (Zell.), they strongly preferred that host in olfactometer tests, following its odor in 85 per cent of the trials as opposed to only 15 per cent toward Meliphora grisella (F.) a factitious host. However, when parasites reared from Meliphora were given the same choice the degree of preference was altered, 65.8 per cent for Anagasta and 34.2 per cent for Meliphora. Thus while the preferred host remained preferred, the degree of preference was influenced by pre-imaginal conditioning. Thorpe and Jones also concluded that this shift in preference would be of no consequence in the performance of the parasite because, under natural conditions, this choice of hosts does not exist.

In mass-rearing programs using Aphytis, it is customary to rear the parasites on a factitious host for a variety of reasons (Huffaker, et al., 1962; DeBach, 1960a). If pre-imaginal conditioning were to occur in Aphytis in such a program, it might have a deleterious impact on their performance in the field when they were released. This would have its most serious implications in an integrated-control program where control of a diaspine scale species was dependent on intermittent release of great numbers of Aphytis. If their success in the field was lessened because their host-preference had been shifted during their ontogeny, the parasites might not achieve the level of control necessary for the program's success. Thus it seemed important to investigate whether pre-imaginal conditioning occurs in Aphytis.

\section{MATERIALS AND METHODS}

Using the same materials and procedure previously described, the female parasite in each replicate was given a choice between two types of hosts, with three individuals of each kind. Both species of parasites were used, each having at least two scale host species which it seemed to prefer equally. A. mytilaspidis was tested using cactus and latania scales. Preliminary observations indicated that the tough cover of latania scale caused the parasites some difficulty in penetrating with their ovipositors. In the first pair of tests, therefore, cactus and latania scale bodies were covered by cactus scale covers to determine whether any preference for one body or the other existed. The first test used $A$. mytilaspidis females reared from cactus scale. The second test utilized individuals reared from latania scale.

After the preference of one body over the other had been tested, other A. mytilaspidis parasites, one set reared from cactus scale and one set reared from latania scale, were offered a choice between cactus scale bodies with cactus scale covers and latania scale bodies with latania scale covers.

A. melinus was investigated in a similar pair of tests using oleander scale and California red scale. Neither of these scales had an exceptionally tough cover, so no test was necessary to show 
TABLE 10

NUMBER OF PARASITE EGGS PRODUCED USING SOFT CACTUS SCALE COVERS IN CHOICE OF BODY TEST BY PARASITES REARED FROM DIFFERENT HOST SPECIES*

\begin{tabular}{|c|c|c|c|c|c|c|c|c|c|c|c|}
\hline \multicolumn{6}{|c|}{$\begin{array}{l}\text { Oviposition of } 4 . \text { mytilaspidis } \\
\text { parasites reared on } \\
\text { cactus scale }\end{array}$} & \multicolumn{6}{|c|}{$\begin{array}{l}\text { Oviposition of } 4 . \text { mytilaspidis } \\
\text { parasites reared on } \\
\text { latania scale }\end{array}$} \\
\hline & $\frac{o}{c}$ & & & $\frac{\mathrm{o}}{\mathrm{L}}$ & & & $\frac{0}{0}$ & & & $\frac{\mathbf{o}}{\mathbf{L}}$ & \\
\hline 1 & 0 & 2 & 1 & 1 & 1 & 2 & 1 & 1 & 2 & 1 & 1 \\
\hline 2 & 1 & 1 & 0 & 1 & 0 & 1 & 1 & 0 & 1 & 1 & 1 \\
\hline 1 & 0 & 0 & 1 & 2 & 0 & 1 & 1 & 1 & 0 & 0 & 1 \\
\hline 1 & 1 & 2 & 1 & 0 & 0 & 0 & 2 & 0 & 0 & 0 & 1 \\
\hline 1 & 1 & 1 & 0 & 1 & 3 & 0 & 1 & 0 & 2 & 0 & 0 \\
\hline 0 & 0 & 1 & 1 & 8 & 1 & 1 & 1 & 1 & 1 & 1 & 0 \\
\hline 0 & 1 & 0 & 1 & 0 & 2 & 1 & 1 & 0 & 1 & 0 & 1 \\
\hline 2 & 1 & 1 & 1 & 1 & 0 & 0 & 1 & 0 & 1 & 2 & 1 \\
\hline 1 & 1 & 1 & 2 & 2 & 1 & 0 & 1 & 0 & 1 & 1 & 1 \\
\hline 1 & 0 & 2 & 1 & 0 & 2 & 0 & 1 & 1 & 1 & 1 & 2 \\
\hline 0 & 2 & 1 & 0 & 0 & 3 & 2 & 1 & 1 & 1 & 1 & 1 \\
\hline 1 & 0 & 0 & 1 & 1 & 2 & 1 & 1 & 1 & 1 & 1 & 1 \\
\hline 3 & 1 & 2 & 2 & 0 & 0 & 2 & 0 & 1 & 1 & 1 & 0 \\
\hline 0 & 1 & 1 & 1 & 1 & 1 & 0 & 0 & 1 & 1 & 1 & 1 \\
\hline 2 & 1 & 1 & 0 & 2 & 0 & 0 & 1 & 1 & 0 & 1 & 0 \\
\hline 0 & 1 & 1 & 1 & 0 & 2 & 1 & 0 & 1 & 2 & 8 & 0 \\
\hline 0 & 1 & 0 & 1 & 1 & 1 & 1 & 1 & 0 & 0 & 1 & 1 \\
\hline 1 & 0 & 0 & 0 & 0 & 0 & 0 & 2 & 0 & 2 & 1 & 0 \\
\hline 0 & 0 & 2 & 0 & 1 & 1 & 0 & 0 & 0 & 0 & 1 & 1 \\
\hline 1 & 0 & 2 & 1 & 1 & 1 & 0 & 1 & 0 & 0 & 0 & 1 \\
\hline - & - & - & - & - & - & 1 & 8 & 0 & 0 & 1 & 1 \\
\hline- & - & - & - & - & - & 1 & 1 & 1 & 1 & 1 & 1 \\
\hline \multicolumn{2}{|l|}{ Totals } & 52 & & & 53 & & & 48 & & & 56 \\
\hline$X^{2} \mathrm{val}$ & & & & & & & & $\begin{array}{l}0.6 \\
0.0\end{array}$ & & & \\
\hline
\end{tabular}

t Seo footnoto tablo 1.

that the bodies were preferred equally. Female parasites were isolated in vials as usual, but after eclosion they were combined with males for 1 hour to allow mating; after 1 hour the male was removed, and the female was used in a test.

The size of the scale body can influence the number of eggs laid on it (Finney and Fisher, 1964) so oleander scale bodies and covers approximately the same size as the red scale bodies and covers were used. (The 50-day-old oleander scale normally used to rear $\boldsymbol{A}$. melinus is considerably larger than the third instar red scale.) Approximately equal body sizes were used so that the parasites would not lay the majority of their eggs on oleander scale simply because of size alone, as this would obscure any preference for the scale species as a species.

\section{RESULTS}

Tables 10 and 11 show results of the A. mytilaspidis tests. Even though no discrimination was made between scale bodies, and cactus scale was preferred over latania scale because of its softer cover, it is clear that a shift in preference was exhibited, and a $\mathrm{X}^{2} 2 \times 2$ test* confirms that the shift is significant. The A. mytilaspidis parasites reared from cactus scale prefer that host more than do the $A$. mytilaspidis parasites reared from latania scale. This is the same sort

\footnotetext{
- Yates correction factor applied.
} 
TABLE 11

NUMBER OF PARASITE EGGS PRODUCED USING CACTUS SCALE (SOFT COVER) AND LATANIA SCALE (HARD COVER) IN CHOICE TEST BY PARASITES REARED FROM DIFFERENT HOST SPECIES*

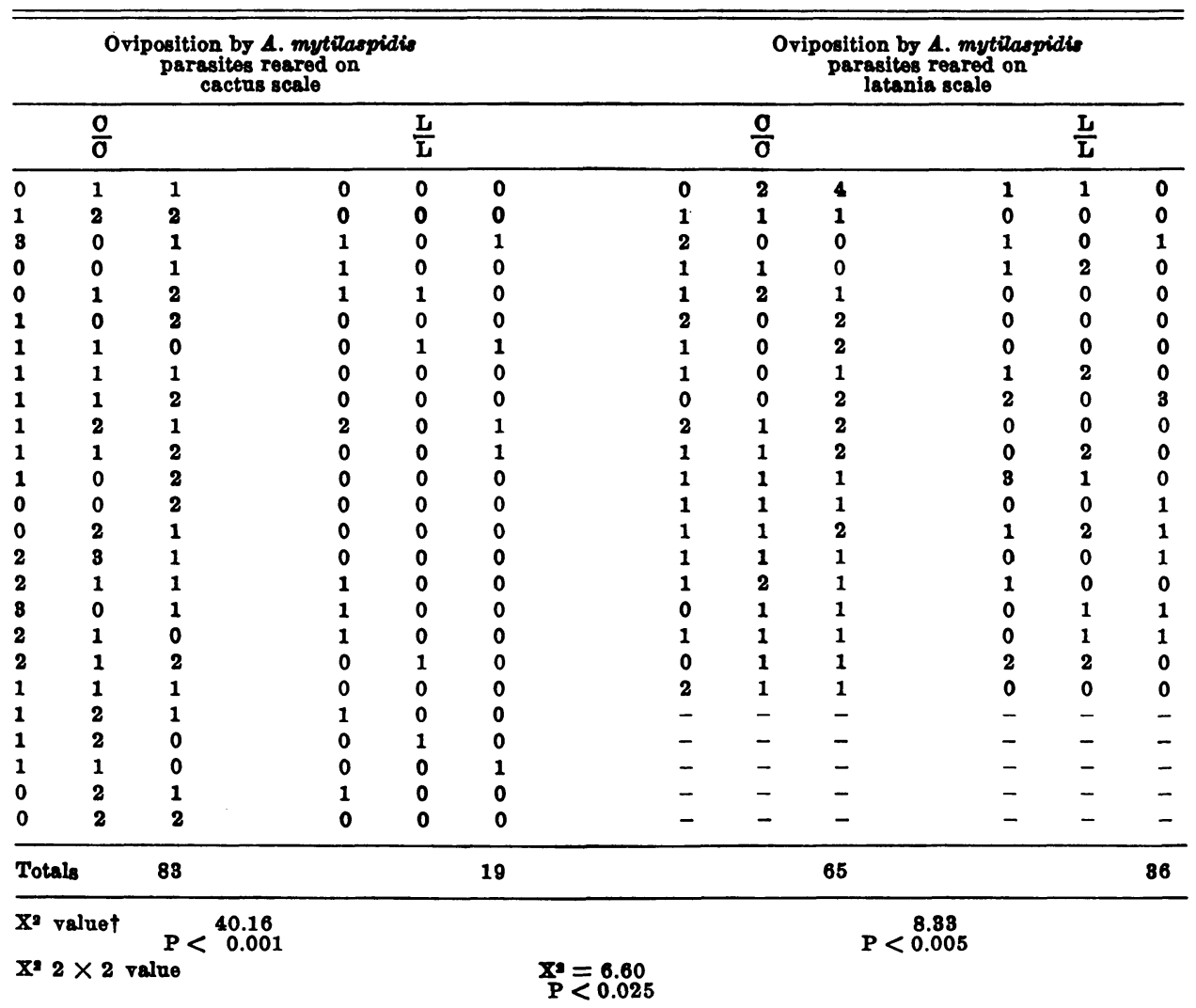

* See footnote table 1.

+ See footnote table 2.

of shift in preference reported by Thorpe and Jones (1937) and indicates that pre-imaginal conditioning had occurred.

In view of results (table 10) showing that latania-reared parasites made no distinction between cactus scale bodies and latania scale bodies, it is difficult to account for this conditioning. A possible explanation lies in the rigidity of the latania scale cover. A parasite which had developed on latania scale must, under cramped conditions, chew a hole in the scale cover in order to gain exit after emergence. This must be at least as formidable a task as that faced by the adult attempting to drill through the cover with her ovipositor. An unquantified observation made during maintenance of the $A$. mytilaspidis culture was that, in comparing latania scale and cactus scale as hosts, many more parasites (after eclosion from the pupa) died while trying to vacate latania scale covers than cactus scale covers. Perhaps the closer, longer contact of the adult parasite with the latania scale as a result of the extra effort required for escape, causes the shift in preference. If so, this may represent an instance of latent learning or imprinting. Hymenopterous insects have shown the greatest capacity for learning (Ebeling and Reierson, 1969). 
TABLE 12

NUMBER OF PARASITE EGGS PRODUCED USING CALIFORNIA RED SCALE AND OLEANDER SCALE IN CHOICE TEST BY PARASITES REARED FROM DIFFERENT HOST SPECIES*

\begin{tabular}{|c|c|c|c|c|c|c|c|c|c|c|c|}
\hline \multicolumn{6}{|c|}{$\begin{array}{l}\text { A. melinus reared } \\
\text { on red scale }\end{array}$} & \multicolumn{6}{|c|}{$\begin{array}{l}\text { A. melinus reared } \\
\text { on oleander scale }\end{array}$} \\
\hline & $\frac{\mathbf{R}}{\mathbf{R}}$ & & & $\frac{0}{0}$ & & & $\frac{\mathbf{R}}{\mathrm{R}}$ & & & $\begin{array}{l}0 \\
0\end{array}$ & \\
\hline 0 & 1 & 0 & 3 & 0 & 0 & 2 & 0 & 2 & 2 & 0 & 1 \\
\hline 0 & 1 & 0 & 2 & 1 & 0 & 0 & 1 & 4 & 2 & 1 & 0 \\
\hline 0 & 0 & 0 & 1 & 0 & 1 & 1 & 0 & 2 & 0 & 0 & 0 \\
\hline 0 & 0 & 0 & 0 & 1 & 0 & 1 & 2 & 0 & 2 & 3 & 2 \\
\hline 0 & 0 & 2 & 0 & 0 & 0 & 0 & 0 & 0 & 0 & 2 & 1 \\
\hline 0 & 0 & 0 & 0 & 0 & 1 & 0 & 0 & 3 & 1 & 1 & 0 \\
\hline 0 & 0 & 1 & 0 & 0 & 0 & 2 & 1 & 0 & 0 & 0 & 1 \\
\hline 0 & 0 & 0 & 2 & 0 & 0 & 1 & 0 & 0 & 2 & 2 & 0 \\
\hline 2 & 2 & 1 & 8 & 2 & 1 & 0 & 0 & 0 & 1 & 0 & 0 \\
\hline 0 & 2 & 0 & 0 & 0 & 0 & 0 & 1 & 0 & 0 & 0 & 0 \\
\hline 0 & 0 & 0 & 0 & 2 & 0 & 0 & 2 & 0 & 0 & 0 & 0 \\
\hline 4 & 2 & 0 & 1 & 1 & 0 & 0 & 0 & 0 & 2 & 0 & 2 \\
\hline 2 & 0 & 0 & 0 & 0 & $\mathbf{2}$ & 2 & 2 & 0 & 0 & 0 & 0 \\
\hline 1 & 0 & 0 & 0 & 0 & 1 & 0 & 1 & 2 & 2 & 0 & 2 \\
\hline 8 & 0 & 0 & 2 & 2 & 0 & 1 & 0 & 2 & 1 & 1 & 1 \\
\hline 3 & 0 & 2 & 2 & 1 & 0 & 1 & $\mathbf{3}$ & 1 & 1 & 1 & 4 \\
\hline 1 & 0 & 0 & 0 & 2 & 0 & 8 & 8 & 1 & 1 & 0 & 1 \\
\hline 0 & 2 & 0 & 0 & 0 & 1 & 0 & 0 & 0 & 0 & 2 & 0 \\
\hline 0 & 2 & 0 & 0 & 1 & 0 & 1 & 0 & 8 & 0 & 0 & 2 \\
\hline 2 & 0 & 0 & 2 & 1 & 1 & 1 & 0 & 1 & 0 & 0 & 0 \\
\hline 0 & 0 & 1 & 1 & 0 & 1 & - & - & - & - & - & - \\
\hline 8 & 0 & 1 & 1 & 0 & 2 & - & - & - & - & - & - \\
\hline 2 & 0 & 2 & 2 & 1 & 1 & - & - & - & - & - & - \\
\hline 8 & 0 & 0 & 8 & 0 & 1 & - & - & - & - & - & - \\
\hline \multicolumn{2}{|c|}{ Totals } & 48 & & & 53 & & & 58 & & & 47 \\
\hline & & & & & & & & & & & \\
\hline
\end{tabular}

* See footnote table 1.

$\uparrow$ See footnote table 2.

Table 12 presents results for $A$. melinus on red scale and oleander scale, equally suitable hosts for that species. No discrimination was made in oviposition between scale hosts, and we may conclude that pre-imaginal conditioning in $A$. melinus does not occur in the interaction between oleander and California red scale, and that it would be no problem in an integrated control program where $A$. melinus was massreared on oleander scale and released for control of California red scale.
The equal number of eggs produced by $A$. melinus on equally suitable hosts (table 12) contrasts markedly with the strong discrimination demonstrated by A. mytilaspidis when presented a choice between suitable and unsuitable hosts (table 2). The results further substantiate the conclusion that ovipositor stimulation causes Aphytis to exercise discrimination in their oviposition behavior when hosts are not equally suitable, but lack discrimination when hosts are equally suitable.

\section{HOST STINGING AS AN ELEMENT IN HOST SUITABILITY}

Although many species of Hymenoptera possess venom and are capable of stinging and paralyzing the host or prey, apparently many others do not or 
at least never use their stinging apparatus. Doutt (1959) says:

The parasitic Hymenoptera may or may not paralyze or kill their hosts prior to oviposition. Some species apparently never inject venom into the host; and in other species, it is obviously essential that the host be killed or paralyzed before it is suitable for the development of immature parasites.

The venom itself is a secretion of the female's acid gland (Beard, 1952; Ratcliffe and King, 1967).

A search of the literature was made to discover the incidence of host stinging among ectoparasites. Articles by Beard (1952), Doutt (1957), Jackson (1937), Lloyd (1956), Simmonds (1956) and Ullyett (1936) all verify that the host is stung, resulting in paralysis or subsequent death. In these cases, the host is either a lepidopterous larva or pupa or a dipterous larva or pupa. Two cases were found where paralyzation involved homopterous hosts. Hagen and van den Bosch (1968) cite Wilbert $(1964$, p. 348$)$ as saying Aphelinus does paralyze its aphid host. Doutt et al. (1966) report that in the autoparasitic Coccophagoides utilis Doutt, a parasite of the olive scale, Parlatoria oleae (Colvee), an unmated female inactivates the host pupa or prepupa (another female of her own species), but that a mated female does not harm the scale when ovipositing on it.

Host stinging has been reported in Aphytis. DeBach and Landi (1961) describe the deep-probing actions of $A$. lepidosaphes and suggest that these movements are concerned with the dispersion of a paralytic agent, since the host becomes paralyzed and preserved. DeBach and Sundby (1963) report that the three species of Aphytis attacking red scale sting the body twice to paralyze it before oviposition. Inas- much as Aphytis attacks only sessile and relatively motionless diaspine scale hosts, the need for host paralysis is not obvious, unless paralysis means prevention of molting as well as muscular inactivation. Even so, the ability of adult Aphytis to prevent host molting has never been specifically demonstrated.

Quayle (1911) observed that immature stages of Aphytis (Aphelinus) were never found in molt or adult female red scale stages, and this fact indicated a cessation of scale growth. $\mathrm{He}$ attributed this cessation to the larval parasite:

The effect of the parasite on the host seems to be the only explanation for the fact that molting may occur later, and before the parasite has developed. The feeding of the parasite seems to check the development of the scale as soon as it is attacked, or soon thereafter.

Because Aphytis species are all ectoparasites, a diaspine scale attacked by such a parasite would become an unsuitable host if it molted soon enough to slough off the parasite's eggs or larvae. If, however, the ovipositing parasite could prevent such molting, she could render late instar hosts suitable for her progeny. Indeed, lack of this ability may be a factor in limiting the host range of certain Aphytis species.

The purpose of these tests is to demonstrate whether certain species of Aphytis have the capability as adults to stop development or prevent molting in their hosts.

California red scale is particularly well-suited for these experiments. The scale is bisexual and Flanders (1951) states that in its development the female has three nymphal instars, the first two followed by a molt, and the male has two nymphal instars, a prepupa, and a pupa, all but the last followed by a molt. Aphytis parasites can 
attack all stages except first instars, molts and adults (Quayle, 1911). California red scale thus has five stages where parasite oviposition can occur and where scale development can be terminated: female second and third instar, and male second instar, prepupa and pupa. Prevention of molting would be indicated when a scale, attacked by a parasite but with the egg removed, did not molt into the next stage. To utilize the five stages it was necessary to identify them accurately. The author consulted McKenzie (1956) who, after Ferris (1942), described the general developmental life cycle of armored scales and Quayle (1938) who gave further information applying specifically to red scale. Some additions were made by the author to the identification of the five stages of scale given below:

\section{Second instar}

\section{Female scale}

One exuvium present; scale body free from scale cover.

Third instar

Two exuvia present; scale body free from scale cover.

\section{Male scale}

Second instar

Scale body tear-drop shaped; eyes indistinct to dark black.

Prepupa

Posterior tip of body truncate; wing and antennal covers present; mouthparts no longer attached. Pupa

Style projecting from posterior tip of body; leg sheaths conspicuous.

All but the first exuvia of the male are delicate and membranous and difficult to use in detecting molting. It was decided not to use third instar female scales in tests described below as their continued development ceases unless they become mated. Thus, not having a means of confirming successful mating I could not tell whether develop- ment was terminated by parasite activity or lack of mating.

\section{MATERIALS AND METHODS}

Lemons bearing the four useful stages of California red scale were placed in a culture of $A$. melinus to obtain oviposition. Covers were removed to locate scales bearing a single parasite egg but otherwise appearing turgid and healthy; the eggs were removed. Over-stung, host-fed and desiccated scales were not considered. An excess of such scales was prepared to allow for attrition due to undetected host-feeding and desiccation. The lemons were then placed in a humidity chamber. Control scales on separate lemons were handled in a similar manner with the exception of the exposure to parasites.

Twenty-five test and control scales of each stage were examined for vitality and occurrence of molting. Vitality was confirmed by turgidity, body movement in response to probe stimulation, and, in some cases, by wax production from pygidial glands. Test scales of second instar females, second instar males, prepupal males, and pupal males were examined in 10, 20, 7 and 7 days respectively. Control scales were examined in $10,5,1-2$ and 1-2 days respectively. The differences in time were related to differences in rate of development among the various scale stages.

\section{RESULTS}

Table 13 gives results of the tests just described. Though they all remained alive, scales attacked by parasites failed to develop into the subsequent stage, while the controls all molted, many more than once. The experiments have also demonstrated that, for both sexes of California red scale, intact scale covers are not necessary for successful molting, provided humidity is high enough. Most second instar control males molted not only once but 
TABLE 13

RESPONSE OF IMMATURE CALIFORNIA RED SCALE TO PARASITE STINGING

\begin{tabular}{|c|c|c|c|c|c|c|}
\hline \multicolumn{7}{|c|}{ Test } \\
\hline $\begin{array}{c}\text { Scale stage } \\
\text { and number } \\
\text { nsed }\end{array}$ & $\begin{array}{l}\text { Number } \\
\text { days held } \\
\text { until } \\
\text { checked }\end{array}$ & $\begin{array}{c}\text { Number } \\
\text { with } \\
\text { necrotic } \\
\text { marks }\end{array}$ & $\begin{array}{l}\text { Number } \\
\text { showing } \\
\text { movement }\end{array}$ & $\begin{array}{l}\text { Number } \\
\text { Turgid }\end{array}$ & $\begin{array}{c}\text { Number } \\
\text { producing } \\
\text { wax }\end{array}$ & $\begin{array}{l}\text { Number } \\
\text { Molting }\end{array}$ \\
\hline $\begin{array}{l}25 \text { \& } \\
\text { Second instar }\end{array}$ & 10 & 0 & 25 & 25 & 6 & 0 \\
\hline $\begin{array}{l}25 \sigma \\
\text { Second instar }\end{array}$ & 20 & 0 & 25 & 25 & 8 & 0 \\
\hline $\begin{array}{l}25 \sigma^{\prime} \\
\text { Prepupae }\end{array}$ & 7 & 0 & $\bullet$ & 25 & $t$ & 0 \\
\hline $\begin{array}{c}25 \sigma^{\circ} \\
\text { Pupao }\end{array}$ & 7 & 0 & $\star$ & 25 & $t$ & 0 \\
\hline \multicolumn{7}{|c|}{ Ohock } \\
\hline $\begin{array}{c}\text { Scale stage } \\
\text { and number } \\
\text { used }\end{array}$ & $\begin{array}{c}\text { Number } \\
\text { days } \\
\text { held } \\
\text { until } \\
\text { checked }\end{array}$ & & $\begin{array}{l}\text { Number } \\
\text { showing } \\
\text { movement }\end{array}$ & $\begin{array}{l}\text { Number } \\
\text { forming } \\
\text { new cover }\end{array}$ & & $\begin{array}{l}\text { Number } \\
\text { molting }\end{array}$ \\
\hline $\begin{array}{l}25 \stackrel{9}{q} \\
\text { Second instar }\end{array}$ & 10 & & 25 & 25 & & 25 \\
\hline $\begin{array}{l}25 \sigma^{\circ} \\
\text { Second instar }\end{array}$ & 5 & & 24 & $t$ & & 9 once \\
\hline & & & & & & 15 twice \\
\hline & & & & & & 1 thrice \\
\hline $\begin{array}{l}25 \text { ఠ" } \\
\text { Prepupae }\end{array}$ & $1-2$ & & $\bullet$ & $t$ & & 25 \\
\hline $\begin{array}{c}25 \sigma^{\circ} \\
\text { Pupae }\end{array}$ & $1-2$ & & * & $t$ & & 25 \\
\hline
\end{tabular}

* These stages do not show movement when probed.

† These stages do not produce wax after molting.

twice, indicating no inhibition of molting. The females not only molted but also produced an entirely new and complete cover by secreting wax from their pygidial glands (fig. 2). This new cover lacked the first exuvium and white cap, but in all other respects appeared to be a normal third instar female scale cover. The exuvium itself had the appearance of a miniature gelatin mold.

The ovipositing parasites did not kill or paralyze the muscles of any of the test scales as shown by the fact that all scales were turgid and displayed contraction movements when poked with a probe. Further evidence of vitality was shown by those second instar males and females which produced wax. If muscular paralysis did occur, these results show that it certainly was only temporary.
However the female alters the scale during oviposition, it is probably done with the ovipositor rather than through host-feeding. If a substance were injected by the parasite from its mouth through the feeding tube and into the scale, the scales would show desiccation or the necrotic marks of host-feeding. None of the scales in any of the tests showed such damage, and yet all did fail to molt.

These experiments demonstrate that Aphytis does host-sting in the preparation of a host suitable for its progeny and it prevents host molting. Unlike those parasites which attack mobile larvae, Aphytis neither immobilizes its host nor kills it by host-stinging, although excessive probing of the host or host-feeding may cause mortality. The function of this stinging in the host- 
parasite relationship is that the adult female can prevent the scale insect from sclerotizing or molting, so that it is still in a suitable condition for larval development when the egg she has laid finally ecloses.

\section{ACKNOWLEDGMENTS}

Support of this study by the $\mathrm{Na}$ tional Science Foundation Grants GB17829, GZ-1373, and GZ-1896 under the direction of Dr. Paul DeBach is gratefully acknowledged. The author is also indebted to Dr. Paul DeBach for his advice and guidance and for suggesting the problem. Thanks are extended to Dr. H. T. Reynolds and Dr.
L. H. Carpelan, as well as Dr. DeBach for reviewing the manuscript. I am also grateful to Stanley Warner, Richard Warkentin, Walter White, Max Badgley and other members of the UCR Division of Biological Control for their congenial cooperation in countless ways during the course of this study.

\section{LITERATURE CITED}

BARTLETt, B. R. and T. W. Fisher

1950. Laboratory propagation of Aphytis chrysomphali for release to control California red scale. Jour. Econ. Ent. 43:802-6.

BEARD, R. L.

1952. The toxicology of Habrobracon venom: a study of a natural insecticide. Connecticut Ag. Exp. Sta. Bul. 562. 27 pp.

COMPERE, H.

1955. A systematic study of the genus Aphytis Howard (Hymenoptera, Aphelinidae) with descriptions of new species. Univ. of Calif. Pub. in Ent. 10(4):271-320.

DEBACH, $P$.

1959. New species and strains of Aphytis (Hymenoptera, Eulophidae) parasitic on the California red scale, Aonidiella aurantii (Mask.), in the Orient. Ann. Ent. Soc. Amer. 52:354-62.

1960a. Commercial mass culture of the California red scale parasite Aphytis lingnanensis. Cal. Ag. Exp. Sta. Bul. 770:1-58.

$1960 \mathrm{~b}$. The importance of taxonomy to biological control as illustrated by the cryptic history of Aphytis holoxanthus n. sp. (Hymenoptera: Aphelinidae), a parasite of Chrysomphalus aonidum, and Aphytis coheni n. sp., a parasite of Aonidiella aurantii. Ann. Ent. Soc. Amer. 53(6):701-5.

1964. Some species of Aphytis Howard (Hymenoptera: Aphelinidae) in Greece. Ann. Inst. Phytopath. Benaki, N.S. 7:5-18.

1969. Biological control of diaspine scale insects on citrus in California. Proc. First Inter. Citrus Symp. 2:801-16.

DEBACH, P. and J. LANDI

1961. The introduced purple scale parasite, Aphytis lepidosaphes Compere, and a method of integrating chemical and biological control. Hilgardia 31:459-97.

DeBACH, P. and R. A. SUNDBy

1963. Competitive displacement between ecological homologues. Hilgardia 34(5):105-66.

DouTT, R. L.

1957. Biology of Solenotus begini (Ashmead). Jour. Econ. Ent. 50:373-74.

1959. The biology of parasitic Hymenoptera. Ann. Rev. Ent. 4:161-82.

DoutT, R. L., C. Huffaker, C. KENNETT, G. FinNeY and S. BroodRYK

1966. Studies of two parasites of olive scale, Parlatoria oleae (Colvee). Hilgardia 37 (9) :219344.

Drooz, A. T. and V. H. Fedde

1972. Discriminate host selection by Monodontomerus dentipes. Environ. Ent. 1:522-23.

Ebeling, W. and D. A. Reikrson

1969. The cockroach learns to avoid insecticides. Cal. Ag. 23:12-15. 
FrRRIS, G. F.

1942. Atlas of the scale insects of North America. Stanford Univ. Press. Series II.

Flanders, $\mathrm{S}$.

1951. Mass culture of California red scale and its golden chalcid parasites. Hilgardia 21:1-42.

Finney, G. L. and T. W. Fisher

1964. Culture of entomophagous insects and their hosts. In Paul DeBach (ed.), Biological control of insect pests and weeds. N. Y. Reinhold Publishing Corp. Pp. 328-55.

HAGEN, K. S. and R. VAN DEN Bosch

1968. Impact of pathogens, parasites and predators on aphids. Ann. Rev. Ent. 13:325-84.

HUFFAKER, C. B., C. E. KENNETT and G. L. FINNEY

1962. Biological control of olive scale, Parlatoria oleae (Colvee) in California by imported Aphytis maculicornis (Masi) (Hymenoptera: Aphelinidae). Hilgardia 32:451-636.

JACKsON, D. J.

1937. Host selection in Pimpla examinator F. (Hymenoptera). Proc. Roy. Ent. Soc. London A. 12:81-91.

LLOYD, D. C.

1956. Studies of parasite oviposition behavior. I. Mastrus carpocapse Cushman (Hymenoptera: Ichneumonidae). Can. Ent. 88:80-9.

LoRd, F. T. and A. W. MAc PheE

1953. The influence of spray programs on the fauna of apple orchards in Nova Scotia. VI. Low temperatures and the natural control of the oystershell scale, Lepidosaphes ulmi (L.) (Homoptera: Coccidae). Can. Ent. 85:282-91.

MC KENZIE, H. L.

1956. The armored scale insects of California. Bul. Calif. Insect Survey. Vol. 5.

QUAYLE, H. J.

1911. The red or orange scale. Cal. Ag. Exp. Sta. Bul. 222:100-50.

1938. Insects of citrus and other subtropical fruits. New York: Comstock Pub. Co. 583 pp.

QUEDNAU, F. W.

1964. An evaluation of fecundity, host-mutilation and longevity on three species of diaspine scales in Aphytis lingnanesis Compere (Hymenoptera: Aphelinidae). S. Afr. Jour. Agr. Sci. 7:521-30.

1965. A technique for identifying mixed populations of six species of Aphytis parasitic on red scale (Aonidiella aurantii (Mask.)) for recognition after recovery from scales collected in citrus orchards (Hymenoptera: Aphelinidae). S. Afr. Jour. Ag. Sci. 8:43-56.

QUEDNAU, F. W. and H. M. HUBSCH

1964. Factors influencing the host-finding and host-acceptance pattern in some Aphytis species (Hymenoptera: Aphelinidae). S. Afr. Jour. Ag. Sci. 7:543-54.

RATCLIFFe, W. A. and P. E. KING

1967. The "venom" system of Nasonia vitripennis (Walker) (Hymenoptera: Pteromalidae). Proc. Roy. Ent. Soc. London Ser. A. 42:49-61.

Simmonds, F.

1956. Superparasitism by Spalangia drosophilae. Ashm. Bul. Ent. Res. 47:361-76.

THORPE, W. H. and F. G. W. JoNES

1937. Olfactory conditioning in a parasitic insect and its relationship to the problem of host selection. Proc. Roy. Soc. London Ser. B. 124:56-81.

ULLYeTT, G. C.

1936. Host selection by Microplectron fuscipennis Zetl (Hymenoptera: Chalcididae). Proc. Roy. Soc. London Ser. B. 120:253-91. 
The journal HILGARDIA is published at irregular intervals, in volumes of about 650 to 700 pages. The number of issues per volume varies.

Single copies of any issue may be obtained free, as long as the supply lasts; please request by volume and issue number from:

\author{
PUBLICATIONS \\ UNIVERSITY OF CALIFORNIA \\ DIVISION OF AGRICULTURAL SCIENCES \\ 1422 South 10th Street \\ Richmond, California 94804
}


